\title{
Differential Susceptibility of the Developing Brain to Contextual Adversity and Stress
}

\author{
W Thomas Boyce ${ }^{\star 1}$ \\ ${ }^{1}$ Departments of Pediatrics and Psychiatry, University of California, San Francisco, San Francisco, CA, USA
}

\begin{abstract}
A swiftly growing volume of literature, comprising both human and animal studies and employing both observational and experimental designs, has documented striking individual differences in neurobiological sensitivities to environmental circumstances within subgroups of study samples. This differential susceptibility to social and physical environments operates bidirectionally, in both adverse and beneficial contexts, and results in a minority subpopulation with remarkably poor or unusually positive trajectories of health and development, contingent upon the character of environmental conditions. Differences in contextual susceptibility appear to emerge in early development, as the interactive and adaptive product of genetic and environmental attributes. This paper surveys what is currently known of the mechanisms or mediators of differential susceptibility, at the levels of temperament and behavior, physiological systems, brain circuitry and neuronal function, and genetic and epigenetic variation. It concludes with the assertion that differential susceptibility is inherently grounded within processes of biological moderation, the complexities of which are at present only partially understood.

Neuropsychopharmacology Reviews (2016) 41, I42-162; doi:I0.1038/npp.2015.294; published online 21 October 2015
\end{abstract}

\section{INTRODUCTION: DIFFERENTIAL SUSCEPTIBILITY TO SOCIAL AND PHYSICAL ENVIRONMENTS}

Differential susceptibility (DS), the pivotal, targeted construct of this review, might be defined in accordance with a 2011 paper by Ellis et al (2011a), as follows:

DS is the disproportionate, neurobiological sensitivity of an individual, group or demographic sub-population to the developmental and health consequences of both imperiling and protective environments. DS to socioemotional and physicochemical environments is acquired in early development, is an interactive product of genetic proclivities and contextual attributes, and is adaptive in the sense of maximizing survival and reproductive success within extant environmental conditions.

Given converging evidence for subgroups of children with these exceptional sensibilities to both risky and supportive social settings, identifying the psychobiological mechanisms by which these susceptibilities are conferred is arguably

${ }^{*}$ Correspondence: Dr WT Boyce, Department of Pediatrics, University of California, San Francisco, 550 16th Street, 4th Floor, 0503, San Francisco, CA 94158-0503, USA, Tel: +415-502-2672,

E-mail: tom.boyce@ucsf.edu

Received 1 June 2015; revised 11 September 2015; accepted 15 September 2015; accepted article preview online 22 September 2015 essential to the enterprise of understanding and potentially influencing DS. In pursuit of such understanding, investigators have explored what might be deemed a causal 'archeology' of candidate mechanisms for DS (see Figure 1) at different levels of scale and complexity. These candidate sources of DS range from children's temperaments and behavioral predispositions, to differences in brain structure and function, to the functional properties of neural circuitry and synaptic biology, and ultimately to allelic and epigenetic variation within the human genome. At each of these levels, mechanisms have been described and studied to which emerging individual differences in DS might be plausibly traced, and the principal goals of this paper are to survey these varied archeological levels of explanation, to identify the level or levels to which DS might be causally linked, and to offer a provisional view of how the multiple mechanistic levels of description might themselves be related.

\section{Harbingers of a Novel Developmental Process}

In the recent, closing decade of the twentieth century, observations began to appear in the developmental neuroscience literature suggesting a reinterpretation of how individual differences produce variation in the consequences of early adversity and stress. In a 1995 paper appearing in Psychosomatic Medicine, Boyce et al (1995b) reported unexpected findings from two studies examining the interactive influences of environmental stressors and 


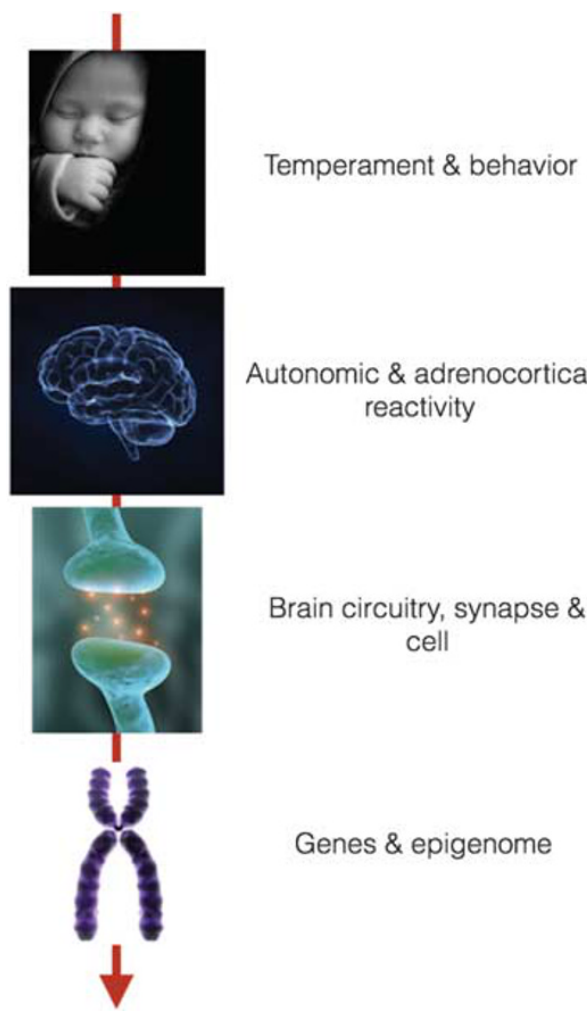

Figure 1. An 'archeology' of mechanisms for differential susceptibility to social conditions.

biological stress reactivity on the incidence of respiratory illnesses in young children. In both studies, one indexing reactivity as autonomic nervous system (ANS) responsivity to laboratory challenges, and the other assessing functional and enumerative measures of immune responses to school entry stress, children with the highest levels of neuroimmunological reactivity showed-as hypothesized-the highest rates of illness under conditions of high naturally occurring stress. A further, unanticipated finding, however, was that the lowest rates of illness, within both samples, were found for equally high reactivity children reared in low-stress, highly supportive, and nurturant family environments. This pattern of interaction-highly reactive children showing either the highest or lowest rates of illness in the sample, contingent upon the character of the social environment-was speculatively attributed to a 'biological sensitivity to the character of the social world':

We suggest that important individual differences exist in children's psychobiologic responses to stressful, challenging conditions and that such differences may be responsible, at least in part, for the unevenness in morbidity experience characteristically found among children within a given social setting. We further-and more speculatively-propose that exaggerated psychobiologic reactivity may reflect a relative deficit in selfregulatory capacity, which results in a heightened sensitivity to the character of the social world. Highly reactive individuals may therefore show either exceptional vulnerability or exceptional resilience, depending on the level of stress and adversity that characterizes the ambient social environment. (Boyce et al, 1995b)

A second, 1997 commentary by Belsky (1997), on a metaanalysis of studies examining the effect of maternal sensitivity on infant attachment security (De Wolff and Van IJzendoorn, 1997), suggested that the modest effect sizes typically found in such studies might be attributable to differences in infant sensitivity:

...it seems possible that one reason effect sizes appear limited in these and other studies of rearing influence is that children vary in their susceptibility to rearing experience-either in general or specifically with respect to attachment security. Were this so, then it might well be the case that the discerned effect size both over- and under-estimates the impact of mothering on attachment security. Evolutionary thinking... leads me to wonder whether the time has come to test more systematically the proposition that not all children are similarly affected by the same rearing experience.

Both the papers of Boyce et al (1995b) and Belsky (1997) had been anticipated in the earlier writing of Wachs and Gandour (see, eg, Wachs and Gandour, 1983) that an 'organismic specificity' underlies such variation in environmental effects, that is, a 'differential reactivity by different individuals to similar early environmental stimulation... [that makes] individual differences a central consideration in early environmental research.' This convergence-of multiple lines of study upon a theory of differential susceptibility to social environmental conditions-was thus an instantiation of convergent scientific discovery: ie, the historical view that discoveries are often made concurrently, by multiple investigators, when a line of thinking or experimentation 'ripens' into an accessible and novel theoretical account (Merton, 1973). By the mid-1990s, several paths of investigation, with differing points of origin, had begun to intersect upon DS to social contexts as an emergent and parsimonious account for the diverse developmental outcomes found among children reared in both highly aversive and highly supportive social environments.

\section{Gathering Evidence}

In the years since the advent of these converging theories, Boyce and Ellis (2005), Ellis et al (2005), as well as Belsky $(1997,2005)$ embedded DS within a framework of evolutionary theory. Van IJzendoorn and BakermansKranenburg (2012a) began examining the broad heterogeneity of developmental and behavioral outcomes from early interventions as a signal of differential, genetic susceptibility, and Del Giudice et al (2011) extended and advanced DS theory by introducing an Adaptive Calibration 
Model addressing the long-term, differential calibration of stress-responsive systems.

Other investigators, from a variety of fields, have documented DS to environmental influences in subgroups of children and youth as compared with the majority of their peers who demonstrate a corresponding equanimity of health effects to all but the most extreme rearing circumstances. Boyce and colleagues (Essex et al, 2011a; Obradovic et al, 2010, 2011; Thomas et al, 2013), for example, developed methods for identifying children with high physiological reactivity to standardized laboratory challenges, as well as their downstream immunologic effects, as biomarkers of DS. Although excessive activation of these systems had been previously regarded in the adult literature on stress reactivity as a risk factor for disease, these investigators repeatedly observed that highly reactive children sustained either unusually high or unusually low rates of illness and disorder, contingent upon the character of their naturally occurring social environments. In a parallel extension of earlier work, Belsky and colleagues (Belsky et al, 2009; Belsky and Pluess, 2013; Pluess and Belsky, 2011) argued that variation in infant temperaments reflect differences in developmental plasticity and showed how children with difficult temperaments manifest the most or least problem behaviors, depending upon their early exposures to poor- or goodquality child care. In a third, programmatic body of research, Bakermans Kranenburg and Van IJzendoorn (2007, 2011) established the existence of genotypic differences that act as DS factors, changing both the consequences of early environmental exposures and the outcomes of early interventions.

The work of all three groups, as well as that of multiple other investigators, became the focus of a recent 10-paper special section of Development and Psychopathology (Ellis et al, 2011a, b; Essex et al, 2011a; Knafo et al, 2011; Kouros et al, 2010; Manuck et al, 2011; Obradovic et al, 2011; Pluess and Belsky, 2011; Poehlmann et al, 2011; Whittle et al, 2010). These studies, demonstrating this greater susceptibility of neurobiologically responsive children to both positive and negative aspects of their environments, have now implicated a wide variety of:

- stressors and adversities, including paternal depression (Cummings et al, 2007), marital conflict (El-Sheikh, 2005; El-Sheikh et al, 2007; Obradovic et al, 2011), parental psychopathology (Shannon et al, 2007), and overall family distress (Obradovic et al, 2010);

- positive environmental features, including parental warmth (Ellis et al, 1999), beneficial experiences and exposures (Pluess and Belsky, 2012), and supportive interventions (Bakermans-Kranenburg et al, 2008); and

- defining biological parameters, including physiological reactivity (see, eg, Alkon et al, 2006; Boyce et al, 1995a), differences in brain circuitry (Whittle et al, 2010), and gene polymorphisms (Bakermans-Kranenburg and Van IJzendoorn, 2006; Knafo et al, 2011; Manuck et al, 2011).

\section{Differential Susceptibility in Evolution}

An introductory essay by Ellis et al (2011a) to the special issue of Development and Psychopathology summarized this body of initial work, advancing the argument that individual differences in neurobiological susceptibility are adaptive and have been conserved through fluctuating selective pressures that generate different fitness payoffs across varying social, physical, and historical contexts. As such, DS theories directly challenge the prevailing diathesis-stress model, in which children with 'difficult' (or negatively emotional) temperaments, or who carry certain 'risk alleles,' are those most likely to sustain maladaptive development or acquire psychopathological conditions, such as depression, when exposed to adversity. Rather than simply amplifying risk, DS theorists argued that variation in neurobiological susceptibility to the environment represents a core mechanism in the genesis and regulation of alternative patterns of human development.

For example, Boyce et al (2005) and Ellis et al (2005) posited a context-sensitive endophenotype rendering a subset of children unusually susceptible to the riskinducing and development-enhancing influences of negative and positive early social environments, respectively. In more stressful contexts, they argued, such highly sensitive, 'orchidlike' individuals would likely do poorly, whereas in supportive, predictable settings, the same individuals would show even stronger outcomes than their robust, relatively resilient, 'dandelion-like' peers, who like dandelions thrive and flourish in all but the worst conditions. Sensitivity to context, they further argued, would have served the survival and reproductive fitness of both groups and individuals within environments of evolutionary adaptedness: by fostering vigilance to threat in conditions of adversity and by more effectively garnering nurturance and support within conditions of abundance and peace. Boyce et al (2005) and Ellis et al (2005) thus further hypothesized that, as a consequence of early conditional adaptations, a curvilinear, U-shaped relation would be found between early exposures to environmental adversity and the development of stressreactive neurobiological profiles. As subsequently confirmed by a number of reports (see, eg, Ellis et al, 2005; Engert et al, 2010; Gunnar et al, 2009; Lorber et al, 2013; Seery et al, 2010), high reactivity phenotypes disproportionately emerge within both highly stressful and highly protected early social environments, resulting in the predicted U-shaped association.

Van IJzendoorn and Bakermans-Kranenburg (2012a) further argued that a heightened susceptibility trait would likely not have emerged and survived within a substantial human subpopulation if it had not carried an adaptive advantage somewhere in reasonably prevalent ecological conditions. Pluess and Belsky (2011) also hypothesized that fetal programming might shape susceptibilities to postnatal environments, producing a variation in plasticity as a bethedging strategy against uncertain futures. All such theories converged on evolutionary explanations of why and how 
individuals vary systematically in their sensitivity or 'permeability' to experiential and contextual influences on development and health.

In a further case for the evolutionary adaptedness of high sensitivity phenotypes, the research of Suomi and colleagues (Barr et al, 2004b) at the NIH Primate Center has shown much the same constitutional differences in sensitivity to risk-engendering and risk-protective social conditions among young rhesus macaques. In more stressful contexts, highly sensitive, 'orchid-like' young monkeys are likely to do poorly, whereas in supportive, predictable settings, the same individuals show far better outcomes than their robust, relatively insensitive, 'dandelion-like' peers. Strong evolutionary arguments have thus been made for the conservation of environmental sensitivity within rearing environments of evolutionary adaptedness. Such sensitivity appears to influence not only the rates and severity of morbidity but also the timing and pace of important developmental transitions, such as puberty (Ellis et al, 2011b). This characteristic, which may become increasingly trait-like over the course of development, appears to emerge as a conditional adaptation, garnering signals from the early social environment about the inherent levels of threat, adversity, support, and nurturance that the growing child is likely to encounter and calibrating stress-responsive biological systems to optimize survival, health, and developmental well-being (Ellis et al, 2006, 2011a; Hane and Fox, 2006). (This inference is based on cross-sectional evidence that the stability of stress reactivity increases over developmental time. Observed correlations in reactivity levels across time, for example, approximate: 0.30-0.0.40 in infants (Alkon et al, 2011), 0.25-0.50 in preschool children (Boyce et al, 1995a), 0.55-0.60 in adolescents (Matthews et al, 1990), and 0.50-0.75 in college undergraduates (Cacioppo et al, 1994) On the other hand, the very few longitudinal studies addressing the larger question of whether DS increases or decreases over developmental time have had mixed conclusions. Belsky and Pluess (2013) found that a $\mathrm{G} \times \mathrm{E}$ interaction revealing DS faded over time, as did the recent work reported by Windhorst et al (2015). Berry et al (2013), on the other hand, reported an increase in DS from the pre-kindergarten period to fifth grade.)

\section{Moderation and Mediation}

DS intrinsically involves some form of biological moderation of the effects of environmental exposures on developmental and life outcomes, and such moderation is usually detected with a cross-product, interaction term in a linear regression model. Reiss et al (2013) usefully point out that such significant interaction terms could signal four distinctive interpretations, each of them legitimate, ie, that:

- biology is influencing individuals' responses to environmental stress;

- biology may amplify sensitivity to environmental conditions, both positive and negative;
- heritable, biological differences may fit some environments better than others; or

- some biological characteristics may only become evident in particular environments.

The authors go on to suggest several categories of evidence and study designs that might credibly differentiate these varied interpretations. These points are acknowledged and well taken, noting that the four interpretations are not necessarily mutually exclusive, but the argument here focuses singularly on the form of moderation in which individual biological characteristics determine differences in sensitivity or 'permeability' to environmental effects.

Moderation thus entails an amplification in some individuals, or a dampening in others, of the potency of both nurturant, protective environments and risky, endangering environments. Such shifts in potency invoke what epidemiologists call effect modification (Fletcher et al, 2012), what social and developmental scientists refer to as moderator or interaction effects (Aiken and West, 1991), and what statisticians and methodologists have defined as an analytic setting in which: (1) a moderator variable $\mathrm{A}$ is antecedent in time to another independent variable $\mathrm{B},(2) \mathrm{A}$ and $\mathrm{B}$ are not correlated, (3) the potency or strength of A's and B's relation to the outcome $\mathrm{O}$ is approximately equal, and (4) the potency of $\mathrm{B}$ as a risk factor for the outcome $\mathrm{O}$ is different for subgroups $A_{0}$ and $A_{1}$ (Kraemer et al, 2001). Common to each is this combination of precedence, correlation, and potency that delineates the formal conditions for DS, where a preexisting variation in context sensitivity, uncorrelated with the current, measured social context, results in differing outcomes among individuals exposed to the same protective or hazardous environment.

DS thus offers one plausible and empirically validated response to a core developmental question, ie, 'What are the origins of the extravagant dissimilarities in human development and phenotype?' It does so by claiming that variation in context sensitivity is an important point of origin, among others, for the rich, evolutionarily conserved diversification of human phenotypes. Another, entirely separate and distinctive set of questions, however, is that surrounding the possible mechanisms of DS:

- What are the functional mediators of context sensitivity, ie, the biological or other means from which DS is derived?

- What levels of scale and complexity best or most usefully capture the sources of DS, and how are such levels related?

- Is there a core biological principle or process-a figurative 'fundamental particle'-underlying DS to social environments?

A consideration of mechanism will be crucial for a deep understanding of the DS process, for an articulated neurobiological science of individual context sensitivity, and for the formulation of novel and effective interventions to mitigate the risk-engendering 'downside' of DS and to catalyze its benefits (Pluess and Belsky, 2012). A reasonable 
and historically fitting place to begin lies in the early descriptions of DS as a developmental by-product of temperament and behavioral 'style.'

\section{TEMPERAMENT, BEHAVIOR, AND SUSCEPTIBILITY}

Individual differences in children's responsivity to environmental challenge were first noted and recorded in the domain most readily accessible to systematic observation without instrumentation: that of behavioral predisposition and temperament. It was against a backdrop of Hippocratic beliefs in the inherent determinism of behavior by admixtures of the four essential bodily humors that Immanuel Kant (1800) built his counterpoint ethics of human autonomy and rational freedom (Larrimore, 2001). Kant viewed temperament as a fundamental element of human nature, in persistent and creative tension with the agentic rationality and freedom that together make an ethics of human behavior possible. Temperamental differences in sensitivity to context were also anticipated in Freud's invocation of a 'protective barrier against stimuli' and in Eysenck's theory of introversion as protection from overarousal. Derivative in part of Greek philosophy, Kantian views of temperament, and early theories of development and personality, it was the seminal observations of Alexander Thomas and Stella Chess, in the 1950s New York Longitudinal Study, that cataloged the behavioral predispositions of human infants along dimensions such as activity level, emotional intensity, behavioral regularity, and sensory sensitivity (Thomas and Chess, 1984). They noted how temperamental extremes, at either end of behavioral dimensions, could become sources of pathological outcomes when challenged by conditions at home, school, or play yard or how even a lack of 'fit' between particular infant temperaments and parental styles could have maladaptive consequences. Following in this clinical-observational tradition, psychologists Mary Rothbart (Rothbart and Bates, 1998) and Jerome Kagan (1989, 1994) examined temperament within a framework of behavioral 'reactivity' and varying sensory thresholds of response to auditory, visual, and social stimuli. Kagan viewed reactivity as constitutive of extreme behavioral phenotypes such as shyness and behavioral inhibition and recognized the underlying biological substrates of those phenotypes within children's measured physiological responses to experiences of novelty and challenge (Kagan et al, 1988). Kagan's students, such as Nathan Fox (Fox et al, 2001, 2005), along with others (Leppanen and Nelson, 2009), have pushed the biology of temperamental inhibition even more deeply into its neurobiological origins, exploring the antecedents of anxiety and panic disorder in the neural biases of emotion-processing brain structures and circuitries. Nonetheless, even at the level of behavioral observation, it is apparent that powerful, visible differences in sensitivity to context, especially contexts involving novelty and challenge, offer important insights into the genesis of developmental psychopathology.

\section{Conservation of Temperamental Variability}

Such thinking, about temperamental differences that guide sensitivity to rearing and learning contexts, led Belsky (1997) to propose, on evolutionary grounds, that natural selection may have maintained genes for both 'conditional' and 'alternative' developmental responses to early environments as a form of bet-hedging against uncertain futures. Conditional (or 'plasticity') strategies would be closely shaped by environmental factors to better fit the organism to the future environment anticipated by early experience. On the other hand, alternative strategies would be mostly fixed and less amenable or 'plastic' to environmental influence. Parents would thus maximize their chances of achieving reproductive success and passing their allelic variants on to a new generation by diversifying their progeny's susceptibility to rearing influence. The same would be true of the children themselves, as siblings share half of the same genes and if one child benefited from parental influence, so would the other less susceptible sibling, via shared genes. Thus, from the (unconscious) perspectives of both parent and child, DS to rearing and perhaps other environmental factors and processes were considered to be evolutionarily advantageous. Arguing then on largely theoretical grounds, Belsky realized that DS-in the form of temperamental differences in behavior-was an evolutionary precondition for adaptive fitness. As noted above, such thinking, about the adaptive advantages of conserving differences in environmental susceptibility, was foreshadowed by the writings of Wachs (1983), Rutter (2006), and Garmezy (1985) on how genes and environments must be interactively involved in the genesis of psychopathological phenotypes.

\section{The 'Highly Sensitive Person'}

Another set of seminal observations within clinical settings and among adult patients reached interestingly parallel conclusions in the work of Aron and Aron (Aron, 1997; Aron and Aron, 1997). They posited a genetically based trait - sensory processing sensitivity-comprising 'a deeper cognitive processing of stimuli that is driven by higher emotional reactivity' (Aron et al, 2012). The 'highly sensitive person' thus appears more responsive to environmental cues, more reflective on how such cues relate to past experience, more risk averse, and less impulsive-all of these characteristics driven by stronger, both negative and positive emotional reactions. Commensurate with Belsky's bet-hedging argument, Aron and Aron further suggest the emergence of an adaptive 'meta-personality,' evolutionarily selected within multiple species as a means of ensuring differences in the degree of coupling between behavior and environmental stimuli, ie, conditional and alternative developmental strategies. Thus, differing predispositions along the dimension of shy to bold, sensitive to nonresponsive have been found in the behavioral reactivity of infant rhesus macaques to novelty and threat (Suomi, 1987), in the intrinsic, interindividual aggressiveness within several fish 


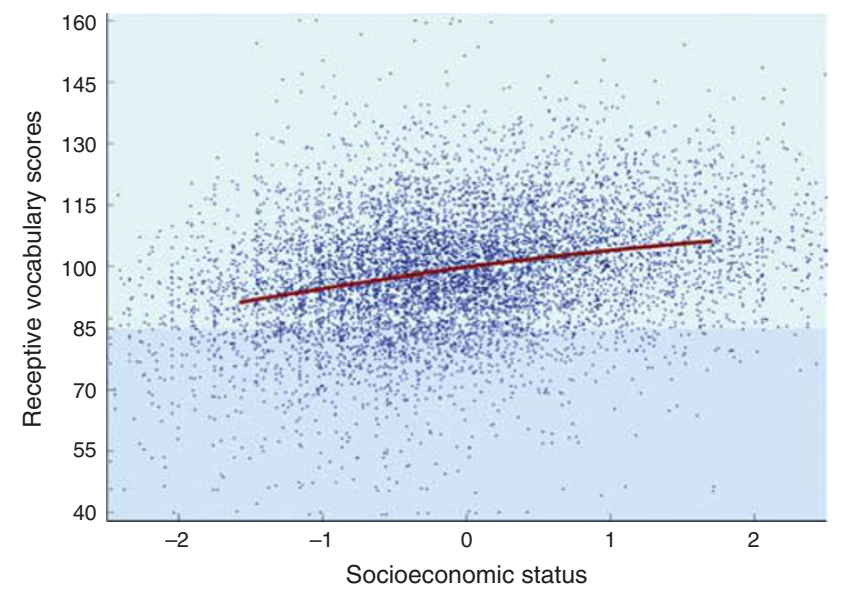

Figure 2. Receptive vocabulary scores by socioeconomic status in the National Longitudinal Study of Children and Youth (Willms, 2002).

and bird species (Koolhaas et al, 1999), and in the foraging behavior ('rovers' vs 'sitters') of fruit flies under varying environmental conditions (Burns et al, 2012; Sokolowski, 2010).

In sum, on both theoretical and empirical grounds, and across multiple species, there is evidence for behavioral mechanisms that both reflect individual differences in context sensitivity and mediate the influence of those differences on developmental and health end points. The pervasiveness of such differences-spanning the visible and quantifiable dimensions of shyness and boldness, introversion and extroversion, novelty avoidance and novelty seeking, and sensory sensitivity and insensitivity-appears to reveal a fundamental dimension of organismic behavior that persists across developmental time and extends across phylogeny. This remarkably expansive range of susceptibility to contextual effects suggests not only the viability of endophenotypes over the entire range but the actual conservation of such phenotypes over evolutionary time.

\section{AUTONOMIC AND ADRENOCORTICAL REACTIVITY}

Behavioral differences expressing the individual's level of environmental susceptibility are coupled reliably, but moderately, with two principal, peripheral stress response systems - the corticotrophin-releasing hormone (CRH) or adrenocortical system and the locus coeruleus-norepinephrine (LC-NE) system-that are themselves reflective of varying degrees of contextual sensitivity. Prompted by the exuberant variability found within associations between social environmental conditions and developmental outcomes (see, eg, the association between socioeconomic status (SES) and literacy scores in Figure 2), Boyce et al (1995a, b) began to explore, as noted briefly above, whether the 'noise' inherent in such associations might in reality not be noise at all, but rather the 'music' to which our best scientific ears should be attuned. In part, this perspective was informed by the realization that noisy variability seemed to persist despite strong methodological efforts: to sharpen the validity of the measurement instruments employed, to maximize structural design strengths by moving, for example, from crosssectional to prospective, longitudinal studies, and to control carefully for the potentially obscuring effects of confounding variables and biased selection of study samples. Despite all such methodological revision and fine-tuning, the remarkable variability has persisted in the work of multiple investigators, suggesting perhaps that real and informative story of these associations lay not in the question 'Is SES (or stress or social isolation) a predictor of literacy scores (or health or educational attainment)?', but in the question, 'Why are the literacy outcomes of children from a given level of SES so extraordinarily varied?'

\section{Autonomic Reactivity in Middle Childhood}

To examine this latter question, Boyce et al (1995a) constructed standardized, laboratory-based protocols designed to accurately assess children's physiological responses to a set of age-appropriate, challenging, and moderately stressful tasks for both 3-8-year-old children and infants and toddlers (Alkon et al, 2006). The two principal stress response systems centered in the human brain but manifested in peripheral physiology were monitored: (1) the CRH system (also known as the hypothalamic-pituitary-adrenocortical (HPA) axis) that is responsible for the output of the glucocorticoid cortisol with its multiple physiologic functions and roles; and (2) the LC-NE system that ignites the 'fight or flight' response of the ANS, plays a key role in information processing and decision making (Nieuwenhuis et al, 2005) and, in interaction with opiate systems, may be responsible for individual differences in stress vulnerability (Van Bockstaele et al, 2010). In the early work of Boyce et al (1995a), the CRH system was indexed as salivary cortisol and the LC-NE system was measured via impedance cardiography as preejection period (PEP, sympathetic ANS branch) and respiratory sinus arrhythmia (RSA, parasympathetic ANS branch). Children's measured physiological responses to tasks, such as an interview by a previously unknown examiner, digit span recitation, a drop of lemon juice on the tongue, and watching emotion-evoking video clips, were broadly varied in magnitude and pattern (Quas et al, 2014) and were then utilized as moderator variables in epidemiologic studies examining naturally occurring social conditions as predictors of developmental and health outcomes.

Figure 3 shows a composite of results found over a 30-year period of study for outcomes as varied as presyndromal psychopathology (see, eg, Obradovic et al, 2011), injuries in children (Boyce, 1996) and rhesus macaques (Boyce et al, 1998), respiratory illness incidence (Boyce et al, 1995b), and memory for a stressful event (Quas et al, 2004). In each case, the pattern of findings showed high reactivity children sustaining the highest levels of morbidity under conditions of 


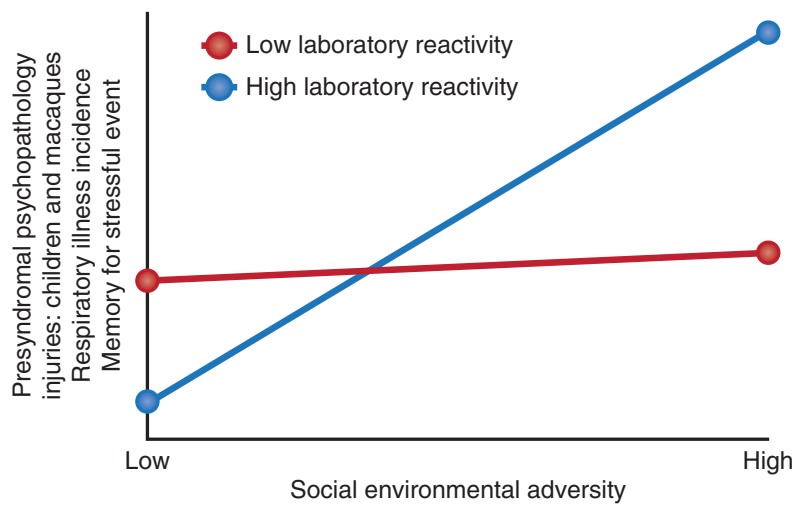

Figure 3. Cumulative results from studies of adversity $\times$ reactivity interactions predicting developmental and health outcomes. The figure is a stylized representation of the general form of interaction effects found in multiple studies over 20 years of research.

stress and adversity, but the lowest morbidity rates in the absence of such adversity; highly reactive individuals had either the worst or best outcomes of the entire study samples, contingent upon the character of their environmental conditions. In contrast, $80-85 \%$ of children with low or average physiological reactivity in the laboratory showed a relative indifference to social environmental circumstances, with little or no escalation in maladaptive outcomes under stress. In metaphorical shorthand, Boyce and Ellis (2005) referred to the former high-reactivity children as 'orchid children,' reflecting their highly variable outcomes contingent upon environment, and the latter, low-reactivity children as 'dandelion children,' signifying their capacities for thriving in all but the very worst environments.

Such findings have also been reported to extend to developmental end points with known linkages to health risks. As shown in Figure 4, the work of Ellis et al (2011b) reported how ANS reactivity and the quality of parenting interacted to predict the timing and tempo of puberty in a cohort of Wisconsin youth. Although low-reactivity youth showed average linear trajectories of pubertal development irrespective of observed parental support, individuals with high laboratory levels of ANS reactivity showed either the steepest trajectories (associated with risk for earlier sexual debut, teen pregnancy, and sexually transmitted diseases) or the flattest trajectories, not even entering puberty until 12.5 years of age. Thus, even for physical maturation over time, reactive, context-sensitive children showed either the riskiest or most protective trajectories, depending upon the socioemotional character of the immediate family environment, whereas low-reactivity children exhibited average trajectories without variation by family conditions.

The work of other investigators has substantially corroborated and extended the findings summarized above, by moving from mostly cross-sectional to longitudinal study designs. Conradt et al (2013) utilized high baseline RSA as a sensitive marker of infants' attunement to their environment and found that highly attuned infants raised in securely

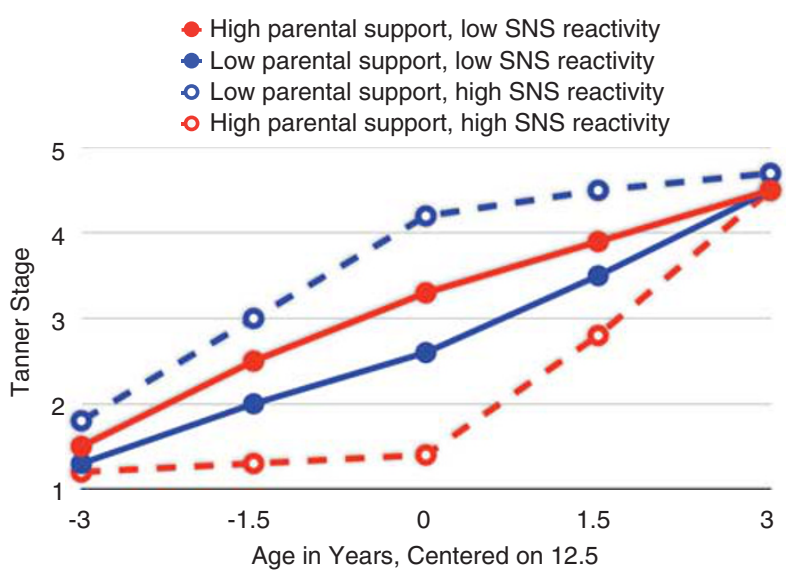

Figure 4. Observed parental support $\times$ sympathetic reactivity interactions predicting timing and tempo of pubertal development (Ellis et al, 2011b).

attached parental environments had the lowest levels of problem behaviors at 17 months of age. In contrast, highly attuned (high baseline RSA) infants in settings of disorganized attachment had the greatest number of behavior problems, and low RSA infants showed moderate levels with no differences by attachment security. Eisenberg et al (2012) also provided positive but more qualified confirmation, showing that children with moderate to high baseline RSAs at 18 months were more likely to be low in parent-reported aggression at 54 months as environmental quality (measured as SES and marital adjustment) increased, whereas aggression was unrelated to environmental quality among those with low RSAs.

\section{Adrenocortical Responsivity}

The seminal work of Gunnar and colleagues (see Talge et al, 2008 for a brief review) began with a concern for the adrenocortical concomitants of fearful and behaviorally inhibited temperaments. Such research eventually led to corroborative observations of adrenocortical reactivity as an indicator of DS to environmental settings. Bolten et al (2013), for example, have shown that newborn neurobehavioral reactivity to a still-face paradigm moderates associations between mothers' cortisol reactivity during pregnancy and infants' emotion regulation at 6 months of age. Specifically, newborns with higher reactivity showed either the best or worst emotional regulatory skills 6 months later, conditional upon mothers' HPA reactivity during pregnancy. In a study by Rudolph et al (2010) children's cortisol responses to a peer-oriented social challenge task moderated associations between reports of peer victimization and teacher ratings of children's aggression. Victimization was associated with aggression among children showing high, but not low, cortisol responsivity, and high HPA responders showed beneficial effects on aggression when children were exposed to low levels of victimization. Finally, in the paper by Obradovic et al (2010) cited above, cortisol reactivity to a 
set of age-appropriate laboratory stressors also moderated an association between family adversity and children's prosocial behavior during the kindergarten year. Cortisol-responsive children showed either the highest or lowest levels of such behavior, depending upon levels of a composite adversity measure comprising financial stress, marital discord, harsh parenting, and other family difficulties.

These studies collectively demonstrate that DS can be recognized and measured within physiological parameters indexing both basal activation and reactivity in the LC-NE and CRH systems. Using relatively noninvasive measures, such as heart rate, blood pressure, PEP, and salivary levels of $\alpha$-amylase and cortisol, investigators have consistently identified children who exhibit an exaggerated sensitivity to aspects of their social environments, sustaining unusually poor outcomes in environments of adversity but exceptionally positive adaptive outcomes in supportive and nurturing social contexts.

\section{BRAIN CIRCUITRY, SYNAPSE, AND CELL}

The next level down in this deepening 'archeology' of DS mechanisms lies within the remarkable complexity of the brain: ie, the vast circuitry comprising over 100 trillion synapses, 86 billion neurons, and 85 billion nonneuronal cells that together constitute the single most complex physical object in the known universe (Herculano-Houzel, 2009). Here, using a remarkably diverse and growing panoply of technological and computational biologic approaches, investigators have begun to reveal the specific brain structures and regions, neural networks, neurotransmitters, and neuronal functions that could potentially underlie exceptional susceptibilities to the social world. As in the levels highlighted above, there is an emerging scientific consensus on how 'sensitivity to context' may be instantiated within an intricate and compelling neuroscience.

There is, for example, evidence that shyness and introversion, strong behavioral correlates of DS at the prior temperamental level, are related to detection thresholds for pain, auditory, olfactory, and visual stimuli. Various forms of developmental psychopathology involve blunted or exaggerated sensitivities to the social and/or physical world and the hierarchy of neural mechanisms subserving such sensitivity has been increasingly probed. Moving from complex cortical networks and circuitry down to the responsivity properties of individual neurons and synapses, the following represents a range of neural processes by which DS might be biologically embedded and mechanistically explained.

\section{Cortical Sensory Processing Sensitivity}

Cortical plasticity in the developing brain allows experiential modulation of sensory processing sensitivity in a variety of cortical areas. Congenitally deaf individuals born to deaf parents, for example, display enhancements of visual cognition and attention related to reorganizations of multisensory brain regions (Bavelier et al, 2006). Baluch and Itti
(2011) have described recent progress in understanding such top-down attentional processes, defined as CNS effects due to intrinsic expectations, knowledge, and goals that alter attentiveness to behaviorally relevant visual cues. Such effects derive from signaling from higher cortical areas, such as the PFC, as well as subcortical regions, such as the superior colliculus and posterior cingulate cortex, that are strongly connected to and influenced by reward and emotion. The plasticity of sensory cortex may also depend on the capacity to modulate sensory input via the presynaptic gating of thalamocortical synapses (Blundon et al, 2011).

In other documentation of enhanced sensitivity among individuals without sensory deficits, Jagiellowicz et al (2011) found that sensory processing sensitivity in a Chinese adult sample was associated with greater fMRI activation to a change detection task in cortical regions linked to higherorder visual processing such as the right claustrum and the left occipitotemporal, bilateral temporal, and posterior parietal cortex. Similarly, Aron et al (2010), in their program of research on highly sensitive adult phenotypes and in another study on detection of subtle visual cues, found greater activation of frontal and parietal cortex for culturally nonpreferred visuospatial tasks; such differences were strongly associated with individual sensory processing sensitivity. Acevedo et al (2014), in commensurate regional brain activation findings, showed increased fMRI signal in the cingulate cortex, insula, inferior frontal gyrus, middle temporal gyrus, and premotor area among study participants with higher sensory processing sensitivity scores. These results suggest that individual differences in cortical sensitivity are subserved by brain regions involved in higher-order visual processing, sensory integration, empathy, and action planning.

\section{Prefrontal, Dynamic Filtering of Emotional Stimuli}

In another body of work and based on observations of and experiments with orbitofrontal lesion patients, Rule et al (2002) proposed a dynamic filtering theory in which the orbitofrontal cortex, under normal conditions, selects and actively inhibits neural circuits linked to emotional responses, thereby modulating emotional inhibition/disinhibition. The prefrontal cortex (PFC), more generally, the last cortical region to myelinate in development, subserves an expansive range of adaptive behavior, including the maintenance of endogenous visual attention, motivation, novelty detection, inhibitory control and decision making, and empathic involvement (Szczepanski and Knight, 2014; Zelazo and Carlson, 2012). Deficits in the filtering role of the orbitofrontal PFC are analogous to those incurred in attentional and memory processes with lesions in the dorsolateral PFC. Although inferences about PFC functions have been derived from observations of lesioned patients, there is substantial variability in the filtering capacities of the PFC in even neurotypical individuals, and such variability could play a role in differential susceptibility to social contextual experiences. 
Prefrontal electroencephalographic (EEG) asymmetry has also been long known to index temperamental differences in emotional valence and predispositions toward approach/ withdrawal behaviors (Davidson and Hugdahl, 1995; McGilchrist, 2009). Left frontal asymmetry is linked to positive emotion and approach/appetitive motivations, whereas right asymmetry is associated with experiences of negative emotion, fearfulness, and withdrawal/avoidance motivations (Davidson, 1995; Willner et al, 2013). The same appears to be true in some non-human species. More recently, Missana and Grossmann (2015) have demonstrated the emergence of asymmetrical frontal responses in infants to displays of emotional body expressions, beginning sometime between 4 and 6 months of age. This finding aligns with earlier work demonstrating: (1) similarly asymmetrical frontal event-related potential (ERP) responses to emotional expression (Missana et al, 2014); and (2) right tympanic membrane temperature laterality in children and young macaques, possibly reflecting frontal cortex activation asymmetries that is associated with problematic, stressrelated behavior (Boyce et al, 1996, 2002). Stress-related symptoms of depression, for example, are associated with diminished blood flow to the left anterior cingulate and dorsolateral PFC and augmented flow to the right amygdala and ventromedial PFC. In other work, Fortier et al (2014) studied, in the most direct test to date, whether left-right frontal asymmetry in resting, $\alpha$-EEG activity might index DS and thus moderate the known association between low birth weight, as an indicator of a poor-quality intrauterine environment, and attentional or internalizing behavior problems in early adulthood. Confirmatory evidence for DS was found, in that individuals with greater frontal EEG asymmetry had unusually high or low attentional and internalizing problems, depending upon their birth weights, $30+$ years earlier. Adults with left frontal asymmetry who had been born at extremely low birth weight exhibited high levels of attentional problems and withdrawn behavior, whereas those with left frontal asymmetry and normal birth weights had exceptionally low levels of such problems. It was thus left frontal asymmetry, rather than right, that functioned as the moderating DS factor, an interestingly anomalous finding that the authors suggest might be attributable to left asymmetry's linkage to a greater adaptive phenotypic plasticity.

\section{Sensory Gating, Prepulse Inhibition, and Kindling}

Sensory gating is the preconscious filtering of sensory information, and patients with schizophrenia are known to have gating deficits, presumably leading to an overload of sensory information that could play a role in the genesis of psychotic and perceptual symptoms (Bak et al, 2014). One approach to detecting such deficits involves the P50 suppression paradigm. The P50 is a positive wave deflection in the ERP, occurring $\sim 50 \mathrm{~ms}$ following an auditory click. The suppression paradigm measures the degree of P50 reduction following the second stimulus when a pair of auditory clicks is presented $500 \mathrm{~ms}$ apart (Patterson et al, 2008). Although the magnitude of the second P50 wave in normal subjects is $\sim 80 \%$ reduced, patients with schizophrenia and PTSD (as well as bipolar disorder, panic disorder, and Alzheimers disease) show comparatively less suppression of the second P50 waveform (Neylan et al, 1999). Using concurrent EEG and fMRI technology, Bak et al (2014) found the source localization of this deficit in people with schizophrenia lies in the hippocampus and thalamus, possibly involving disturbed GABAergic interneuron function (Vlcek et al, 2014). Myles-Worsley et al (1996) have shown, in monozygotic (MZ) and dizygotic (DZ) twins, that $\mathrm{P} 50$ suppression ratios (ie, the S1/S2 ratio of P50 amplitudes) are under partial genetic control. Furthermore, because the endocannabinoid system has been implicated in the pathophysiology of schizophrenia and cannabinoids disrupt sensory gating, a deficit in auditory stimulus gating has been considered an endophenotype of the disease (Dissanayake et al, 2013). The unconstrained sensitivity resulting from impaired sensory gating may, in the extreme, underlie the perceptual abnormalities seen in schizophrenia and other forms of mental disorder, but could also contribute to the differential sensory sensitivity apparent in some normal subjects.

A second, related, but sometimes dissociated gating process is prepulse inhibition (PPI), a sensorimotor attenuation of the acoustic startle reflex when the stimulus (eg, a loud, pulsatile auditory signal) is preceded, by 30-300 ms, by a weak prepulse stimulus (Holstein et al, 2013). Startle is measured by the eye blink response using electromyographic recordings from the muscle surrounding the eye. Nonspecific deficits in PPI are found in a broad variety of neuropsychiatric conditions, including obsessive compulsive disorder, Gilles de la Tourette's syndrome, and Huntington Disease (Kohl et al, 2013). Patients with attention deficit hyperactivity disorder (ADHD), on the other hand, show deficits in cognitive performance, diminished P50 suppression, but a normal level of PPI. Mouse models have generated evidence for genetic contributions to PPI and have implicated polymorphisms in the COMT (catechol-O-methyltransferase), CHRNA3 (nicotinic cholinergic receptor) and neuroregulin 1 genes in diminished PPI (Powell et al, 2012).

A third set of neurosensitization processes, kindling and long-term potentiation (LTP), originally referred respectively to: (1) animal models in which repeated electrical stimulation of limbic structures led to progressive downregulation of seizure thresholds; and (2) an increase in synaptic strength, lasting hours, following high-frequency presentation of an induction stimulus (Bonin and De Koninck, 2015). The neuronal level signatures of such repeated stimulation are the induction of transcription factors, especially $c-f o s$, increases in transmission of neuromodulators, followed by downregulation of the corresponding autoreceptors on the presynaptic cell membrane (Miller, 2000; Monroe and Harkness, 2005). Recent evidence suggests that a kindlinglike sensitization mechanism may also occur in recurrent 
human depression, where functional changes in neuromodulators and reduced hippocampal and amygdala volumes also occur (see, eg, Maes et al, 2012). Kindling appears to represent, in both the original animal model of seizure induction and in the human model of recurrent depression, a relatively enduring state of neural sensitization and thus a possible mechanism for DS to environmental stressors. Changes in synaptic strength, as occur in LTP, take place through presynaptic alterations in the number of neurotransmitter molecules released and/or through shifts in the type, properties, or numbers of postsynaptic receptors (Xiong and Krugers, 2015). Stress-induced catecholamines from ANS activation and glucocorticoids from the LC-NE system are both capable of facilitating LTP by dynamically regulating $\alpha$-amino-3-hydroxy-5-methyl-4-isoxazolepropionic acid (AMPA) receptors, a postsynaptic glutamate receptor that facilitates fast synaptic transmission. Both kindling and LTP are neurosensitization processes that can arise from highfrequency stimulation of discrete brain regions, and both involve activation of glutamatergic receptors.

Finally, Yap et al (2008) found, in a cross-sectional study of adolescent students, that MRI volumetric measures of amygdala and anterior cingulate cortex were differentially susceptible to maternal aggressive behaviors in their association with children's depressive symptoms, suggesting that parenting may moderate associations between brain structure and mental health symptoms. Bethea et al (2005) showed that female cynomolgus monkeys with greater reproductive sensitivity to stress have fewer serotonergic cell numbers in the dorsal raphe nucleus and diminished expression of the serotonin pathway-related genes, SERT, $M A O-A, 5-H T 1 A$, and $M A O-B$. These observations suggest that both serotonergic neuron number and the expression of serotonin-related genes may be involved in the origin of stress-sensitive phenotypes.

Considered together, these various neuromodulatory processes, ranging from cortical plasticity allowing regulatory changes in unimodal sensory sensitivity to gating mechanisms at the levels of single neurons and synapses, could be plausibly implicated in the sensory sensitivities identified among individuals exhibiting differential susceptibility to environmental effects. Indeed, the report by Fortier et al (2014) showed that frontal EEG asymmetry, one such neuromodulatory process, operated as a possible endophenotype for DS. Although none of these candidate neural mechanisms are mutually exclusive-altered sensory gating, for example, can scaffold cortical plasticity (Blundon et al, 2011) — each offers a tenable neurobiological account for how subsets of individuals could have or acquire special sensitivities to the character of both perilous and protective social environments.

\section{GENES AND EPIGENOME}

Finally, the deepest archeological probe of candidate mechanisms that current biomedical science has achieved lies within the now substantial evidence that genetic and/or epigenetic variation may account for DS to aspects of both social and physical environments. Allelic variation within single genes or empirically derived, composite genetic risk scores (GRSs) can sometimes account, in isolation, for small portions of the variance in important phenotypic outcomes. Examples include $5 \%$ of patients with autism who have rare, loss-of-function mutations in one of $100+$ autosomal genes (De Rubeis et al, 2014) and $2 \%$ of variance in educational attainment that is accounted for by a GRS from a large, genome-wide association study (GWAS) (Rietveld et al, 2013). It may be possible that GRSs based on clusters of genes within known or discoverable biological pathways (ie, gene ontology or gene regulatory networks) could account for substantially greater portions of outcome variance (see, eg, Santra, 2014). DS, on the other hand, always implies interplay with environmental measures, rather than a genetic influence alone, and a variety of studies, both observational and experimental in design, have now reported how either single-nucleotide polymorphisms (SNPs) or combinations of allelic variants are associated with DS to aspects of social and physical environments. Studies of DS resulting from genetic variation are therefore inherently studies of gene by environment $(\mathrm{G} \times \mathrm{E})$ interactions.

\section{$G \times E$ Interactions and Differential Susceptibility}

$\mathrm{G} \times \mathrm{E}$ interactions are genetic and environmental effects on outcomes that are conditional upon each other-eg, the effects of genetic variants becoming apparent only in the presence of specific environmental conditions, or environmental influences being revealed only among individuals of a particular genotype. In animal models from fruit flies (Burns et al, 2012) to rats (Meaney, 2001) and non-human primates (Barr et al, 2004a), new evidence has accumulated that $\mathrm{G} \times \mathrm{E}$ interactions play a role in the genesis of speciestypical and deviant behavior. Though long anticipated, it was only little more than a decade ago that reports began documenting $\mathrm{G} \times \mathrm{E}$ interactions in the longitudinal prediction of human developmental and health outcomes. The papers of Caspi et al $(2002,2003)$ from the Dunedin Multidisciplinary Health and Development Study revealed statistical interactions between functional gene polymorphisms (eg, the MAOA, monoamine oxidase A, and 5HTTLPR serotonin transporter genes) and early environmental conditions (eg, child maltreatment and stressful life events) in the prediction of antisocial behavior and depression/ suicidality. Even in these studies, there were hints of DS, in that children with the highest risk (S/S) alleles of 5HTTLPR had not just the highest probabilities of suicidal ideation and attempts in the highest stress conditions, but also the lowest rates in the lowest stress conditions. This pattern of results suggested that so-called 'risk' alleles might be better conceptualized as 'sensitivity' or 'plasticity' alleles, with differential effects, or even a reversal of effects, in differing environmental circumstances. 
Questions were raised, however, regarding the $5 H T T L P R \times$ stressful events interaction in a meta-analysis of reports that followed the findings of Caspi et al (Risch et al, 2009), and some have more recently dismissed efforts to identify significant $\mathrm{G} \times \mathrm{E}$ interactions within samples of modest size, where such effects have largely been found (see, eg, Duncan and Keller, 2011), attributing most $\mathrm{G} \times \mathrm{E}$ reports to a combination of type I error and publication bias. Further critiques of a $\mathrm{G} \times \mathrm{E}$ approach (see Duncan and Keller, 2011, 2014; Risch et al, 2009) have included the assertions that: (1) most positive $\mathrm{G} \times \mathrm{E}$ studies have modest, underpowered sample sizes of several hundred participants or less; (2) polymorphisms within most of the implicated genes appear to have very small effects; (3) testing statistical interactions in the absence of a genetic main effect is fraught with type 1 errors; (4) a focus on candidate genes (eg, genes for neurotransmitter synthesis, metabolism, and so on) ignore genetic variation in unexamined and noncoding (intronic and intergenic) DNA regions; (5) the current, relatively primitive state of human neuroscience disallows informed selection of more promising candidate genes; (6) most $\mathrm{G} \times \mathrm{E}$ findings have failed to replicate, leading to largely negative meta-analytic evidence; and (7) given the numbers of genetic variants, environmental dimensions, and outcomes of interest, the landscape of possible, dyadic $\mathrm{G} \times \mathrm{E}$ interactions and their outcomes is enormous, raising further concern over a profusion of type I errors. (Interested readers are referred to a paper by Dick et al (2015) that addresses these and other vulnerabilities of $\mathrm{G} \times \mathrm{E}$ research and analyses.)

Despite such multiple critiques, there are substantial arguments-both theoretical and empirical-supporting a claim that $\mathrm{G} \times \mathrm{E}$ interplay must play a mathematical and biological role in accounting for variation in important developmental and health outcomes. Among such arguments are the following:

(1) On purely theoretical grounds, an absence of $\mathrm{G} \times \mathrm{E}$ interactions would imply that: (a) individual differences in environmental effects lie outside the influence of biology and genetics; and (b) natural selection of genetically influenced responses to the environment does not exist-each of which is a contradiction to established biological principles, evolutionary theory, or both (Rutter et al, 2009).

(2) The claim that statistically significant $G \times E$ effects must not be considered in the absence of a significant $\mathrm{G}$ effect is fallacious, as a balanced, crossover interaction will entail a main effect of neither G nor E; the DS model, in fact, specifically posits a crossover interaction. Furthermore, denying a specific $\mathrm{G} \times \mathrm{E}$ interaction on solely statistical grounds is shortsighted without parallel consideration of biological and clinical observations, the results of animal studies, and experimental findings (Rutter et al, 2009).

(3) As pointed out by Rothman and Greenland (2005), all disorders of health and development are, in effect, uniformly both genetic and environmental in the sense that virtually all end points depend upon mutually interactive influences of both. Thus, mental retardation that results from phenylketonuria, a disease often regarded as fully genetic in origin, can be prevented by early, continuing dietary treatment, ie, an environmental intervention. Similarly, in a society in which every citizen smoked a pack of cigarettes per day, lung cancer would be regarded as a solely genetic disorder, as the lack of any variation in exposure to a causal agent (smoking) would preclude discovery of the environmental contribution. In a sense, that conclusion would be valid, because all variation in incidence would then be attributable to differences in genetic susceptibility (Rose, 1985).

(4) There is now emerging empirical evidence that $\mathrm{G} \times \mathrm{E}$ interactions are preeminently potent in their prediction of developmental and biological outcomes. Teh et al (2014), for example, have shown that the variably methylated regions (VMRs) within neonatal methylomes-variation constituting a molecular memory of individual, in utero experience-were best explained by an interaction of DNA sequence polymorphisms and prenatal environments, including maternal smoking, depression, and BMI, as well as infant birth weight, gestational age, and birth order. These $\mathrm{G} \times \mathrm{E}$ interactions, constituting a form of fetal programming, accounted for $75 \%$ of VMRs, whereas genotype alone explained only $25 \%$.

(5) The so-called 'missing heritability'-ie, the difference between phenotypic variance attributable to genetic polymorphisms and total heritability estimates from studies of $\mathrm{MZ}$ and $\mathrm{DZ}$ twins-implies, among other things, interactions between genes and environments. Thus, although only $5 \%$ of variance in height is accounted for by the $\sim 40$ known loci affecting linear growth, twin study estimates of height heritability are set at $80 \%-$ a missing heritability of as much as $75 \%$, presumably attributable to interactions between genes and environments (Duncan et al, 2014). Furthermore, computational modeling of the circumstances under which $\mathrm{G} \times \mathrm{E}$ effects on height can be detected shows that although (a) $G \times$ Es involving only single SNPs go largely unnoticed in simulations using realistic parameter estimates of environmental effects and genetic architecture, (b) well-powered models employing summative GRSs detected pervasive $\mathrm{G} \times \mathrm{E}$ effects (Marigorta and Gibson, 2014).

(6) The flourishing field of epigenetics, defined as 'the structural adaptation of chromosomal regions so as to register, signal or perpetuate altered [gene] activity states' (Bird, 2007), has implicit within it physical, molecular interactions between environments and genes. Epigenetic mechanisms change gene activity or expression in response to environmental conditions by altering chromatin organization without modifying the genetic code of the DNA and by blocking transcription factor 
binding sites (Meaney, 2010). Such a definition carries with it the implication that the epigenome is an environmentally responsive overlay on the genome itself, possibly buffering or moderating genetic variation through up- and down-regulation of gene transcription (Boyce and Kobor, 2015).

Despite legitimate concerns for the replicability of $\mathrm{G} \times \mathrm{E}$ interaction reports, some such effects have been replicated in independent samples (van Winkel et al, 2014), and new evidence for $\mathrm{G} \times \mathrm{E}$ interactions continues to accrue. Although the paper of Risch et al (2009) launched a tide of skepticism regarding $5 H T T L P R \times$ adversity interaction and single studies have indeed sometimes failed to replicate initially promising $\mathrm{G} \times \mathrm{E}$ results, meta-analyses published over the past decade have generally affirmed the candidate gene polymorphism $\times$ environment interactions reported in the single-study findings that preceded them. Thus, the preponderance of meta-analytic reviews addressing functional polymorphisms in candidate genes and their interactions with environmental perturbations has supported, not undermined, the replicability of these findings, including those for MAOA (Byrd and Manuck, 2014; Kim-Cohen et al, 2006; Taylor and Kim-Cohen, 2007), 5HTTLPR (Van IJzendoorn et al, 2012b), BDNF, the brain-derived neurotrophic factor gene (Hosang et al, 2014), and DRD4 (the dopamine receptor) (Bakermans-Kranenburg and Van IJzendoorn, 2011). Although no meta-analyses are yet available for environmental interactions with the COMT, FKBP5 (FK506 binding protein 51), or OXTR (oxytocin receptor) candidate genes, single reports of $\mathrm{G} \times \mathrm{E}$ interactions with each are continuing to appear.

As noted by Kraemer (2012), the research design and mathematical modeling difficulties inherent in detecting and interpreting the cooperation of genes and environments create a 'perfect storm' of methodological challenges. That tempest occupies the dead center, however, of the possibly most fertile and promising arena of contemporary biomedical research: ie, how genes and environments work together to undermine health. The search for reliable $\mathrm{G} \times \mathrm{E}$ interactions may be abetted by the development of both empirical evidence that GRSs associated with developmental phenotypes can discern promising new SNP targets (Rietveld et al, 2013) and computational models suggesting that GWAS approaches to $\mathrm{G} \times \mathrm{E}$ discovery may be more promising than candidate SNP by SNP searches (Marigorta et al, 2014). Indeed, in fields such as psychiatric genomics, the way forward appears to lie in new knowledge of how multiple genes with additive or multiplicative effects, each with incremental influences, are assembled into functional genetic networks that interact with social environmental conditions to produce important phenotypic disorders (Gratten et al, 2014). Thus, $G \times E$ interactions, such as the conjoint influence of genes and environments on differences in human development and health, are the constitutive, elemental sources of DS. Such interactions are defining properties of DS, because all other 'layers' of susceptibility description or detection-temperamental, physiological, or neurobiological-must ultimately rest upon foundational differences in $\mathrm{G} \times \mathrm{E}$ interaction, the gene expression they differentially regulate, and the neurobiological processes they guide.

\section{Allelic Variation and Differential Susceptibility}

With regard to the $\mathrm{G}$ component of such interactions, studies of DS have now amassed a substantial body of work indicating that genetic variation can have a biologically 'sensitizing' effect on the impact of environmental differences. Within infancy and early post-natal life, BakermansKranenburg and Van IJzendoorn (2006) showed, in the earliest reported $\mathrm{G} \times \mathrm{E}$ interaction revealing $\mathrm{DS}$, that preschoolers with the DRD4 exon III 7-repeat allele had either the highest or lowest levels of externalizing behavior problems, contingent upon their experiences of low or high sensitivity parenting, as rated in video-recorded observations of parent-child interactions. Montirosso et al (2015) found that infants with at least one S-allele of the 5HTTLPR gene and mothers evincing low social engagement during play showed greater emotional negativity during the mildly disturbing Still Face procedure, whereas those with the same genetic profile but highly engaged mothers showed the least negativity. Similarly, Babineau et al (2014) demonstrated differential susceptibility among children with the S- and $\mathrm{L}_{\mathrm{G}}$-alleles of the 5HTTLPR gene (the latter polymorphism a variant of the L-allele with a functional effect on mRNA expression similar to that of the S-allele): children with the 'risk' alleles having greater behavioral and cognitive dysregulation when exposed to prenatal maternal depression, but greater regulatory capacities in the absence of such prenatal exposure. Consistent with the findings of both latter studies, Caspi et al (2010) summarized human research, neurobiological evidence, and the results of animal experiments, concluding that allelic variation within the 5HTTLPR gene appears to operate as a genetic promoter of environmental sensitivity.

In other work, Qiu et al (2015) studied interactions between complex variations in the COMT gene, which regulates catecholamine signaling the PFC, and maternal anxiety in predicting individual differences in fetal brain development among human newborns. In one example of such interactions, they found that regional prefrontal cortical thickness decreased with antenatal maternal anxiety among infants who were met homozygotes on the COMT gene but increased among those who were val homozygotes (Qiu et al, 2015). VanZomeren-Dohm et al (2015) examined moderator effects of a polymorphism in the FKBP5 gene that encodes FK506 binding protein 51, a chaperone protein that regulates glucocorticoid receptor (GR) sensitivity. Youth who had been institutionalized in infancy and early life showed increased depressive symptoms when subjected to peer group victimization. Girls with the minor FKBP5 genotype showed DS to victimization: ie, higher symptoms when subjected to higher overt victimization, but lower symptoms 
relative to others under conditions of low victimization. Finally, Sturge-Apple et al (2012) presented evidence for allelic variation in the $5 H T T L P R$ and OXTR genes moderating previously recognized associations between interparental conflict and mothers' parenting practices (the so-called 'spillover effect').

A variety of studies in middle childhood have similarly identified genetic polymorphisms that function as sources of DS. In forthcoming work, Bush et al (2015a, submitted) have shown that children who are met allele carriers in the gene coding for BDNF show either the highest or lowest levels of basal cortisol expression, depending upon the family's income. In another analysis of the same sample of 5-yearold children (Bush et al, 2015b, submitted), the author reports that carriers of the OXTR A-allele have the highest or lowest body mass index percentiles, contingent upon family SES. This latter finding is commensurate with the conclusions of a recent review (Brüne, 2012) that functional polymorphisms in the OXTR gene are associated with sociability, amygdala volume, and differential risk for psychiatric disorders, depending upon the quality of early contextual exposures.

In a meta-analysis of how negative and positive rearing environments are linked to middle childhood developmental outcomes, Bakermans-Kranenburg and Van IJzendoorn (2011) found that children with the less efficient, 7-repeat allele of $D R D 4$ fared less well in negative environments than their counterparts without the genetic 'risk factor,' but also gained most from positive rearing conditions. Bogdan et al (2014) also found 5HTTLPR $\times$ stressful life events interaction in predicting preschool-onset depressive symptoms among 3-5-year-old children. Again, those with the risk allele had either the most or least depressive symptoms, depending upon level of stressor exposure. Grazioplene et al (2013) studied a functional polymorphism in the cholinergic receptor gene CHRNA4 and found that those with the T/T genotype showed DS to child maltreatment effects on the Neuroticism and Openness/Intellect dimensions of personality. Mitchell et al (2014), in analyses from the Fragile Families Study, showed that 9-year-old African American boys with greater genetic sensitivities within the dopamine and serotonin neurotransmission pathways had the shortest telomere lengths (a biomarker for cumulative life adversity) under conditions of disadvantage (low income, low maternal education, unstable, family structures, and harsh parenting). Boys with the same indices of genetic sensitivity had the longest telomere lengths in more advantaged environments. Finally, Zohsel et al (2014) uncovered a moderator effect of the DRD4 gene polymorphism in the link between mothers' prenatal stressors and children's antisocial behavioral outcomes at 8-15 years of age. These findings and others indicate that allelic variation in DNA sequences can itself engender a heightened sensitivity to both negative and positive early social settings.

Within adolescent and young adult populations, and consistent with the DS hypothesis, Belsky and Beaver (2011) found that an index of risk alleles in five candidate 'plasticity' genes (DAT1, DRD2, DRD4, 5HTTLPR, and $M A O A)$ moderated the link between parenting quality and male adolescent self-regulation. In a sample of several hundred African American young adults, Simons et al (2011) found longitudinal evidence for the differential susceptibility of aggressive behavior to environmental adversity among individuals with the combination of the S-allele of the 5HTTLPR gene and the L-allele of the DRD4 dopamine receptor gene. Hankin et al (2011), in three independent study samples, demonstrated 5HTTLPR-related DS to the presence or absence of positive, supportive parenting; youth with the S/S-allele showed the greatest or least positive effect, depending upon the character of the parenting they received. Taylor et al (2006) similarly found that young adults with S/S-allele had greater depressive symptoms if they had experienced early adversity, but lower symptoms in the presence of supportive early environments. Sweitzer et al (2013) reported an interaction between earlylife SES and the 7-repeat allele of the DRD4 gene in the prediction of impulsive economic decision making, such that individuals with the 7-repeat allele and low SES backgrounds showed steeper discounting of delayed but larger rewards in a delay discounting experiment. The 7-repeat allele carriers with no early deprivation, however, discounted future reward less steeply. Chen et al (2011) identified 10 polymorphismsalso in genes related to dopaminergic neurotransmissionthat accounted for $15 \%$ of the variance in scores on Aron's Highly Sensitive Person Scale. Witt et al (2011) showed that homozygotes for the $\mathrm{T}$ allele of the neuropeptide $Y$ (NPY) gene interacted with early adversity showed the lowest ACTH and cortisol responses to the Trier Social Stress Test, whereas subjects with the same genotype but low early adversity had the highest HPA activation. Finally, Laucht et al (2012) found that a homozygous COMT met allele moderated the association between low parental supervision and drinking at 19 years of age; drinking was reduced under conditions of favorable parenting.

As pointed out by Manuck and McCaffery (2014), a major challenge for the DS model from such findings, in all their corroborative diversity, is to account for the apparent functional reversals of the allelic associations across risky and protective environments. One possible explanation the authors advance is that genetic effects on fundamental psychological processes, such as attentional bias, could have opposing effects in differing environments. In one such example, Fox et al (2011) showed that individuals with a low expression form of the serotonin transporter gene (5-HTTLPR) showed stronger biases toward both negative and positive emotional stimuli in an attentional bias modification procedure.

In corroborative animal models of allelic variation and DS, Barr et al (2004b) have demonstrated, in experiments with rhesus macaques, how early rearing conditions, within either mother- or peer-reared groups, interact with the 5HTTLPR promoter polymorphism to predict ACTH expression during separation stress. Peer-reared animals with the L/S genotype had the highest ACTH levels during separations, but lowest 


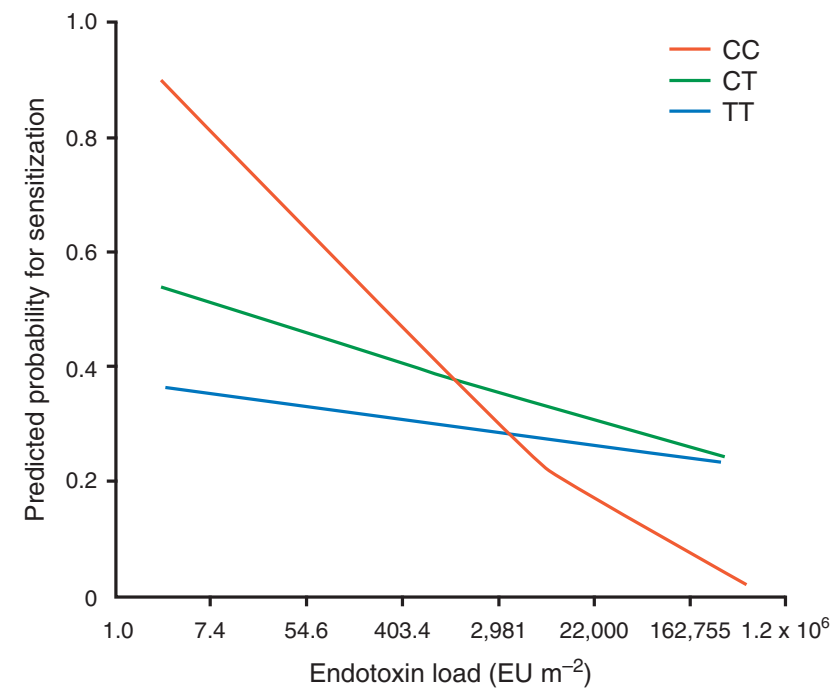

Figure 5. Endotoxin load and CD14 genotype interactions predicting probability of atopic sensitization (from Guerra and Martinez, 2008).

in preseparation, control conditions. Buschert et al (2013) also reported an experiment with transgenic mice bearing 8 copies of a human gene that produces neurotrophic factor $\mathrm{S} 100 \mathrm{~B}$ that is associated with psychiatric disorders but also relates to better therapeutic outcomes in patients. S100B mice showed either reduced or elevated anxiety-related behavior in the open field test, depending upon their exposures in early life to stable or unstable social conditions.

\section{DS to Experimental Interventions}

As comprehensively summarized by Bakermans-Kranenburg and Van IJzendoorn (2015) in a recent review paper, a number of intervention studies aiming to change the character of social environmental exposures have demonstrated how genetic variation can produce DS to, and thus differential efficacy of, the interventions under study. Cicchetti et al (2015), for example, studied genetic moderation of interpersonal psychotherapy (IPT) effects on symptoms among economically disadvantaged women with major depressive disorder. In women with no copies of the CRHR1 TAT haplotype, IPT significantly improved both depressive symptoms and social adjustment; contrary to predictions from previous research, there were parallel findings for women with the LL haplotype of the 5HTTLPR gene. For African American women only, 5HTTLPR genotype operated as a DS factor, with the lowest symptoms among LL women in the IPT group and the highest among LLs in the community care-as-usual group. These provocative findings suggest the possibility that ancestral ethnicity may modify or even reverse the influence of genotypic variation on treatment effects.

Drury et al (2012) from the Bucharest Early Intervention Project studied indiscriminate social behavior (eg, a lack of reticence or inappropriate affection with strangers) among previously institutionalized Romanian children randomized to either placement in family foster care or care-as-usual group in an orphanage. At 54 months of age, children with either the S/S 5HTTLPR genotype or the met BDNF allele showed the highest levels of such behavior if they had remained in the orphanage group, but the lowest levels if placed in foster families. Brett et al (2014), also examining data from the Bucharest Early Intervention Project, found that the high susceptibility allele of the $E R B B 3$ neuroregulin gene predicted the largest corpus callosum volumes in children randomized to the foster care condition, but the smallest volumes among those remaining in orphanages.

In yet another example of DS to an experimental intervention, Scott and O'Connor (2012) conducted a randomized controlled trial of a parenting intervention for 5-6-year-old children showing high levels of oppositional behavior. After 1 year, children with pretreatment evidence of emotionally dysregulated behavior were significantly more responsive to positive changes in parental care due to the Incredible Years intervention. Together, these experiments indicate that differentially susceptible young children may be especially receptive not only to naturalistic changes in their rearing environments, but also to experimentally implemented or induced changes. Each of these experimental results is commensurate, moreover, with the previous findings of Quas et al (2004) that accurate 2-week recall of a mildly stressful event by autonomically reactive 4-6-year-old children was augmented by random assignment to a supportive examiner but diminished by assignment to an unsupportive, emotionally distant examiner; no such differences were identified for the low reactive children.

\section{DS to the Physical Environment}

DS to contextual exposures occurs not only to stressors and adversities in the socioemotional environment, but also to the physical environment. The work of Guerra and Martinez (2008), in a series of groundbreaking papers from the Arizona-based Children's Respiratory Study, has shown how exposures to microbial products early in life, such as that occurring in rural farming communities, confer protection against atopic diseases such as asthma (ie, the so-called hygiene hypothesis that poorer hygienic conditions may be protective against certain immune-mediated disease processes). Protection and risk occur, however, in a genotype-specific manner. Allelic variation in the gene encoding the CD14 cell surface, pattern recognition receptor, for example, interacts with the level of endotoxin exposure in early life to predict the probability of sensitization leading to asthma. Specifically, the $\mathrm{T}$ allele diminishes sensitization under conditions of high endotoxin exposure and amplifies in conditions of low exposure, whereas carriers of the C-allele show much less dramatic effects of varying endotoxin loads (see Figure 5). The T-allele thus confers DS to endotoxin loads in the development of atopic sensitization. 


\section{Epigenetic Variation and Differential Susceptibility}

Variation in epigenetic marks that regulate gene expressionmethylation of $\mathrm{CpG}$ dinucleotides, as well as multiple chemical modifications of the histone protein around which DNA is wrapped within chromatin structure-are also clearly involved as mechanisms of DS to environmental exposures and events. As discussed by Sipahi et al (2014a, b), differences in epigenetic profiles of DNA methylation may help to explain susceptibility and resilience to the emergence of posttraumatic stress disorder (PTSD) following a significant trauma. A variety of recent studies have reported systematic epigenetic differences between individuals sustaining PTSD and healthy survivors following exposures to severe adversity (see, eg, Mehta et al, 2013; Uddin et al, 2010). Furthermore, many such studies reveal epigenetic modifications of genes involved in immune competence and dysregulation, a finding consistent with the known effects of trauma on the functioning of the HPA axis and the immuneregulatory effects of glucocorticoids and CRH. Sipahi et al (2014a) show the conservation of epigenetic mechanisms to control the effects of adversity across mammalian species and identify transcription factor binding motifs in the DNA that share locations with known PTSD-linked CpG methylation sites.

Essex et al (2011b) also reported, using a subsample of children from the Wisconsin Study of Families and Work, epigenetic vestiges of early developmental adversity, as reported by parents during their children's infancy and preschool periods. A decade and half after the parental reports, differential methylation of multiple DNA sites by levels of parental stress was identified in the buccal epithelial cells of the then 15-year-old adolescents. The authors further found that mothers' stressors in infancy were more related to differences in hypermethylation for both girls and boys and that fathers' stressors in the preschool period were associated with hypomethylation primarily for girls. Olden et al (2014), in a recent review of how individual and neighborhood health disparities may arise from exposures to chemical and nonchemical stressors, conclude that epigenetic modifications accumulated over time could plausibly constitute a common, molecular pathway toward susceptibility to the environmental agents of disease. The carcinogenicity of toxic metals such as lead and arsenic is attributable to alterations in DNA methylation and gene expression, and socioemotional stressors also create epigenetic modifications capable of changing brain development and constraining adaptive plasticity. Disadvantaged communities have disproportionate exposures to both physical toxins-through their proximity to polluted industrial sites and contaminated drinking water-and psychosocial stressors-via the excessive presence of noise, chaos and violence-and both forms of environmental assault may yield an epigenetically mediated differential susceptibility to chronic disease and maladaptive development.

Within differential susceptibility theory, however, greater sensitivities to the character of the social world have also been hypothesized to emerge developmentally and responsively via conditional adaptations to the social signals of early life (Boyce et al, 2005; Ellis et al, 2005). Conditional adaptations-such as the polyphenism in wing pattern and coloration found among butterflies emerging from chrysalises during differing seasonal conditions-are fitness-augmenting changes in development in response to early environmental cues (Ellis and Bjorklund, 2012; Gilbert and Epel, 2009; Nederhof and Schmidt, 2012). An important question is therefore whether epigenetic modifications, acquired as a consequence of early environmental signaling, might also be linked to differentially susceptible phenotypes. Suderman et al (2012), for example, studied large, differentially methylated regions centered upon the NR3C1 GR gene in the hippocampi of both rats and humans experiencing substantially different levels or forms of early parental care. The methylation profiles of both species were extensively different in individuals receiving high $v s$ low level (rats) or abusive $v s$ nonabusive (humans) early parental care, with many between-species commonalities in the specific, differentially methylated sites. Beach et al (2014), in a sample of African American youth from working poor communities, found that cumulative socioeconomic adversity and the S-allele of the 5HTTLPR gene interactively predicted promoter region methylation within a group of $200+$ depression-related genes. Youth with the S-allele had either the highest or lowest levels of depression gene methylation, depending upon levels of exposure to povertyrelated stress. Strunk et al (2013) have argued that the increased susceptibility of infants to infectious agents of disease may be due to differential methylation of immuneregulating and other developmentally salient genes. Finally, the Binder laboratory (Klengel et al, 2013), in a landmark report, has demonstrated a differential susceptibility of individuals bearing the AG/AA 'risk' allele of the FKBP5 gene. Such individuals have either higher or lower rates of adult PTSD, conditional upon childhood exposures to sexual and/or physical abuse. Furthermore, the molecular process by which this epidemiologically observed interaction occurs is mediated through DNA demethylation in the glucocorticoid response elements of FKBP5. Specifically, Binder and colleagues (Klengel et al, 2013) found a mediating, three-dimensional molecular event involving demethylation of a $\mathrm{CpG}$ site within an intron of the risk allele. FKBP5 codes for a so-called 'chaperone protein' that alters the function of the GR and impedes the translocation of the GR-glucocorticoid complex into the cell nucleus. The demethylation event, which can occur only during an early critical period and results in a persistent activation of FKBP5, then primes the risk allele carrier for stress-induced overproduction of the chaperone protein, suppression of GR function, HPA axis dysregulation, and a consequent augmentation of risk for PTSD (for a more detailed explanation of these mechanisms, the reader is referred to Boyce and Kobor, 2015 or Szyf, 2013). These observation are collectively among the first to show how chromatin modification and epigenetic marks may constitute actual 
molecular mechanisms for a differential susceptibility to environmental conditions.

\section{CONCLUSION: EMERGENT PROPERTIES OF DYNAMICAL BIOLOGICAL SYSTEMS}

This paper has advanced the argument that individual differences in susceptibility to both positive and negative and both social and physical environments may be detected and mediated at a variety of hierarchically ordered levels of biological description. The field of investigators collectively probing the character and provenance of DS has engaged in an intensive 'archeological dig' in which contextual sensitivity has been examined at multiple layers of biological complexity and scale in both human and animal studies. The result has been a now substantial corpus of evidence, only partially inventoried herein, documenting differences in susceptibility at the levels of temperament and behavior, neuroendocrine physiology, brain structure and function, neuronal sensitization and responsivity, and allelic and epigenetic variation within genomic structure. Implicit within this biobehavioral archeology is the assertion that, although the specific elements unearthed at each level may differ by outcome or environmental feature, the same core process is at work, ie, the differential, neurobiological susceptibility of some individuals to their social and physical environments. Thus, the operative physiological dimension of DS for infectious and inflammatory diseases might be immune-mediated processes, whereas that for psychological disorders might be autonomic or adrenocortical reactivity. The nominated 'fundamental particle' of DS, however-the process almost defining the phenomenon itself-is that of biological moderation: the interactive events by which preexisting biological differences amplify or diminish the consequential effects of environmental conditions on developmental and health outcomes. There are, however, four elemental difficulties or complexities involved in thinking about the claim that DS is, at root, an interactive, moderating biological process.

First, the biological moderation inherent in DS is replicated not simply at each level of complexity, from temperament to histone modification, but across its multiple levels and scales. Johnson and Adler (1993), for example, showed that a transient stressor (the cold pressor test) concurrently caused blood pressure to rise and P50 auditory gating to diminish, suggesting a cross-level linkage of physiologic and neurosensory mechanisms for DS. Similarly, Stevens et al (2001) found that chronic treatment of $\mathrm{C} 3 \mathrm{H}$ mice with corticosterone resulted in a diminished prepulse inhibition of the acoustic startle. It has also been shown that the P300 component of visual ERPs, a measure of neuronal sensitization, is under partial genetic control, revealing greater concordance in P300 amplitude, latency, and manual reaction time for $\mathrm{MZ}$ twins than for DZs (Katsanis et al, 1997) - a linkage from genotypic variation to neurosensitization. Behavioral inhibition, a temperamental trait, is associated with biased responses to both rewards and punishments, bias that is related to functional alterations in striatal function in the brain (Guyer et al, 2006). Sensory modulation difficulties can also be mediated by ANS activation, as both overresponsivity and underresponsivity to auditory stimuli in Autism Spectrum Disorder patients are related to higher sympathetic reactivity (Chang et al, 2012). Common to each such finding, activation or responsivity at one level appears moderately tethered to functionality at another higher or lower level of hierarchical biology-a form of 'loose coupling' that, although possibly thematic within developmental and systems biology, is an as yet poorly understood mode of linkage between levels of susceptibility (Herbert and Ziegler, 2005).

Second, in reflecting upon such connections between different layers of biological processes, Turkheimer (1998) argued, in an influential paper on weak and strong 'biologism', that all mental and social phenomena are finally products of the physical self. 'Weak biologism' is simply a corollary of philosophical naturalism: the view that all psychological processes are by definition physically instantiated, and thus all behavior is biological in principle-a claim that is undeniable but uninteresting. Some psychological phenomena, however, are empirically and causally tied to biological levels of explanation - thus, 'strong biologism'and intervention may be appropriate and effective at that level. It therefore does not necessarily follow that biological accounts are superior to or more useful than those at higher levels of complexity. When our computers produce gibberish, Turkheimer (1998) asserted that such errors are demonstrably underpinned by the programming language we have employed, by the machine language beneath it, and by even the hardware of the computer itself. That does not imply, however, that we fix muddled output by entering the computer, pulling the chip and wiring, and adjusting its structure with microtools. Rather, the appropriate point of intervention is much higher, at the level of the language we ourselves have fed the machine. Similarly, the fact that brain circuitry and DNA underlie, in some manner, DS and the acts of maladaptive behavior it sometimes yields does not in principle imply that the solution lies in reprogramming synapses or altering DNA.

Third, we are left with the question of how garnered knowledge of DS and its effects and foundations might usefully transform our approaches to aberrant behavior, psychiatric disorder, disease, and maladaptive development? The problem with searching for a clear, unitary mechanism linking susceptibility and phenotype is that it implies an unwarranted and possibly misleading simplicity. It implies that some cortical, neural, synaptic, or genomic process linearly accounts for the linkage between context sensitivity and phenotypic outcomes. The reality, however, is that DS is inherently triadic and nonlinear in character. Here, an analogy may perhaps be helpful. In the semiotics of philosophers Charles Sanders Pierce (Hardwick and Cook, 1977) and Walker Percy (Percy, 1991), there is not one but two kinds of natural events in the world: first, dyadic events 


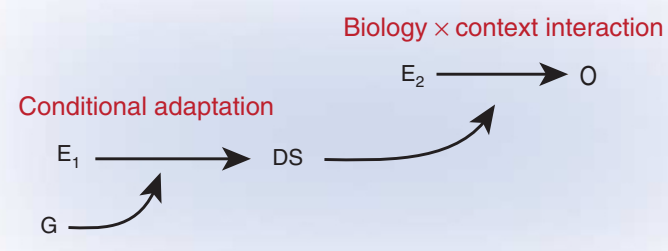

Figure 6. A differential susceptibility model: early environments $\left(E_{1}\right)$ and individual genetic variation (G) shape DS in an early conditional adaptation; later environments $\left(E_{2}\right)$ and biological susceptibility (DS) determine developmental and health outcomes $(\mathrm{O})$ in biology $\times$ context interactions. Such interactions and their triadic linkages to intermediate- and longerterm outcomes are thus arguably both the originating source and the functional mechanism of DS.

that are the familiar subjects of the physical sciences (eg, two pool balls colliding) and are our default models for explanations of the perceived world. Percy (1991) in particular argued, however, that our reliance on dyadic causal models results in our missing something fundamental about the character of human experience. Events involved in naming and language, by contrast (eg, a young child beginning to associate a physical boat with the word 'boat'), are irreducibly triadic, and form the elemental building blocks of human intelligence. Something analogous to this happens in DS, as developmental processes and disorders arise out of the conjunction of external conditions and internal susceptibilities. Just as naming and language involve the triadic linkage of a referent, a signifier and an emergent awareness, developmental and health trajectories stem from the conjunction of environment, biologic susceptibility, and emergent interactive processes. There is something fundamentally triadic about how the convergence of context and constitution guide developmental trajectories toward adaptive or maladaptive end points.

Fourth and finally, among the problematic complexities of this claim is the reality that biology $\times$ context interactions generally, and $\mathrm{G} \times \mathrm{E}$ interactions more specifically, are arguably both the originating source and the functional mechanism of DS. As illustrated in Figure 6, early environments $\left(E_{1}\right)$ and individual genetic variation $(G)$ shape DS in a process of conditional adaptation in early development. The fetus and young infant are increasingly viewed as highly responsive receivers for the intra- and extrauterine signals that disclose present and future conditions, into which the child will be born and ultimately raised. Such signals, along with the individual's indelible genetic profile, calibrate and 'tune' central and peripheral biological processes to maximize survival and fitness. Later developmental environments $\left(E_{2}\right)$, presumably but not lawfully continuous with $E_{1}$, then determine, in conjunction with biological susceptibility, the developmental outcomes $(\mathrm{O})$ that set life course trajectories of health, achievement, and well-being. $\mathrm{G} \times \mathrm{E}$ is thus both the antecedent and operational core of DS.
What then might we do, as scientists, clinicians, and makers of societal policy, with the apparently enduring and pervasive recognition of individuals (and especially children) with exceptional susceptibilities to both the virulent effects of our society's worst social conditions and the salubrious, life-giving influences of its best? Though we may one day reach a level of knowledge where the mechanisms of such susceptibilities can inform social and biological interventions at a multiplicity of levels, perhaps it is sufficient, for now, to simply recognize and acknowledge the extraordinary and problematic sensitivities of a small (though vast in absolute numbers) subset of our children and citizens. From the 1960s to 1991, the federally defined toxic threshold for blood lead levels in children decreased from 60 to $10 \mu \mathrm{g} / \mathrm{dl}-\mathrm{a}$ dramatic reduction in a threshold for clinical action that resulted in the identification and treatment of tens of thousands of US children with damaging exposures to a highly prevalent neurotoxin (Astrin et al, 1987; Wetmur et al, 1991). What drove that societal change of policy between 1960 and 1991 was the recognition that the gene for D-aminolevulinic acid dehydrogenase $(A L A D)$-the enzyme that catalyzes the synthesis of heme, an essential component of hemoglobinhas two allelic polymorphisms, ALAD-1 and ALAD-2. The ASAD-2 allele, which has a prevalence as high as $20 \%$ in some populations, is associated with higher blood lead concentrations for a given level of exposure. Recognition and protection of the most vulnerable and sensitive children resulted in greater protection for all. Hence, so it should be for those of our children with inordinate sensitivities to impoverished neighborhoods and exposures to violence, to family stressors and economic adversities, to harsh parenting and single-parent homes, and to maltreatment, neglect, and abuse. Eliminating the exposures of our most vulnerable children to these malignant conditions with known pathological effects would make our society safer, better, and more healthy for all. Even more compelling, we now understand that the very subgroup of children most sensitive to the developmental and health sequelae of poverty, violence, and despair are the same group most likely to benefit dramatically from exposures to supportive, protective, and encouraging social contexts-contexts that the world and our nation cannot afford not to provide.

\section{FUNDING AND DISCLOSURE}

The author declares no conflict of interest.

\section{ACKNOWLEDGMENTS}

The research and work upon which this review is based was supported by the National Institute of Child Health and Human Development (grant award RO1 HD24718), the National Institute of Mental Health (grant award R24MH081797), the MacArthur Foundation Research Network on Psychopathology and Development, the Sunny Hill Health Centre/British Columbia Leadership Chair in Child Development at the University of British Columbia, the Child 
and Brain Development Program of the Canadian Institute for Advanced Research, and the Lisa and John Pritzker Distinguished Professorship of Developmental and Behavioral Health at the University of California, San Francisco.

\section{REFERENCES}

Acevedo BP, Aron EN, Aron A, Sangster MD, Collins N, Brown LL (2014). The highly sensitive brain: an $\mathrm{fMRI}$ study of sensory processing sensitivity and response to others' emotions. Brain Behav 4: 580-594.

Aiken LS, West SG (1991). Multiple Regression: Testing and Interpreting Interactions. Sage: Newbury Park, CA.

Alkon A, Boyce WT, Davis NV, Eskenazi B (2011). Developmental changes in autonomic nervous system resting and reactivity measures in Latino children from 6 to 60 months of age. J Dev Behav Pediatr 32: 668.

Alkon A, Lippert S, Vujan N, Rodriquez ME, Boyce WT, Eskenazi B (2006). The ontogeny of autonomic measures in 6- and 12-month-old infants. Dev Psychobiol 48: 197-208.

Aron A, Ketay S, Hedden T, Aron EN, Rose Markus H, Gabrieli JD (2010). Temperament trait of sensory processing sensitivity moderates cultural differences in neural response. Soc Cogn Affect Neurosci 5: 219-226.

Aron E (1991). The Highly Sensitive Person: How to Thrive When the World Overwhelms You. Broadway: New York.

Aron EN, Aron A (1997). Sensory-processing sensitivity and its relation to introversion and emotionality. J Pers Soc Psychol 73: 345-368.

Aron EN, Aron A, Jagiellowicz J (2012). Sensory processing sensitivity: a review in the light of the evolution of biological responsivity. Pers Soc Psychol Rev 16: 262-282.

Astrin KH, Bishop DF, Wetmur JG, Kaul B, Davidow B, Desnick RJ (1987). deltaAminolevulinic acid dehydratase isozymes and lead toxicity. Ann NY Acad Sci 514: 23-29.

Babineau V, Gordon Green C, Jolicoeur-Martineau A, Minde K, Sassi R, St-Andre M et al (2014). Prenatal depression and 5-HTTLPR interact to predict dysregulation from 3 to 36 months-a differential susceptibility model. J Child Psychol Psychiatry 56: 21-29.

Bak N, Rostrup E, Larsson HB, Glenthoj BY, Oranje B (2014). Concurrent functional magnetic resonance imaging and electroencephalography assessment of sensory gating in schizophrenia. Hum Brain Mapp 35: 3578-3587.

Bakermans Kranenburg MJ, Van IJzendoorn MH (2007). Research review: genetic vulnerability or differential susceptibility in child development: the case of attachment. J Child Psychol Psychiatry 48: 1160-1173.

Bakermans-Kranenburg MJ, Van IJzendoorn MH (2006). Gene-environment interaction of the dopamine D4 receptor (DRD4) and observed maternal insensitivity predicting externalizing behavior in preschoolers. Dev Psychobiol 48: 406-409.

Bakermans-Kranenburg MJ, Van IJzendoorn MH (2011). Differential susceptibility to rearing environment depending on dopamine-related genes: new evidence and a meta-analysis. Dev Psychopathol 23: 39-52.

Bakermans-Kranenburg MJ, Van IJzendoorn MH, Mesman J, Alink LR, Juffer F (2008). Effects of an attachment-based intervention on daily cortisol moderated by dopamine receptor D4: a randomized control trial on 1- to 3-year-olds screened for externalizing behavior. Dev Psychopathol 20: 805-820.

Bakermans-Kranenburg MJ, Van IJzendoorn MH (2015). The hidden efficacy of interventions: genexenvironment experiments from a differential susceptibility perspective. Annu Rev Psychol 66: 381-409.

Baluch F, Itti L (2011). Mechanisms of top-down attention. Trends Neurosci 34: 210-224.

Barr CS, Newman TK, Lindell S, Shannon C, Champoux M, Lesch KP et al (2004a). Interaction between serotonin transporter gene variation and rearing condition in alcohol preference and consumption in female primates. Arch Gen Psychiatry 61: 1146-1152.

Barr CS, Newman TK, Shannon C, Parker C, Dvoskin RL, Becker ML et al (2004b). Rearing condition and rh5-HTTLPR interact to influence limbic-hypothalamicpituitary-adrenal axis response to stress in infant macaques. Biol Psychiatry 55: 733-738.

Bavelier D, Dye MW, Hauser PC (2006). Do deaf individuals see better? Trends Cogn Sci 10: 512-518.

Beach SR, Brody GH, Lei MK, Kim S, Cui J, Philibert RA (2014). Is serotonin transporter genotype associated with epigenetic susceptibility or vulnerability? Examination of the impact of socioeconomic status risk on African American youth. Dev Psychopathol 26: 289-304.

Belsky $J$ (1997). Variation in susceptibility to environmental influence: an evolutionary argument. Psych Inquiry 8: 182-186.
Belsky J (2005). Differential susceptibility to rearing influence: an evolutionary hypothesis and some evidence. In: Ellis BJ, Bjorklund DF (eds), Origins of the Social Mind: Evolutionary Psychology and Child Development, Guilford: New York, pp 139-163.

Belsky J, Beaver KM (2011). Cumulative-genetic plasticity, parenting and adolescent self-regulation. J Child Psychol Psychiatry 52: 619-626.

Belsky J, Jonassaint C, Pluess M, Stanton M, Brummett B, Williams R (2009). Vulnerability genes or plasticity genes? Mol Psychiatry 14: 746-754.

Belsky J, Pluess M (2013). Genetic moderation of early child-care effects on social functioning across childhood: a developmental analysis. Child Dev 84: 1209-1225.

Berry D, Deater-Deckard K, McCartney K, Wang Z, Petrill SA (2013). Geneenvironment interaction between dopamine receptor D4 7-repeat polymorphism and early maternal sensitivity predicts inattention trajectories across middle childhood. Dev Psychopathol 25: 291-306.

Bethea CL, Streicher JM, Mirkes SJ, Sanchez RL, Reddy AP, Cameron JL (2005). Serotonin-related gene expression in female monkeys with individual sensitivity to stress. Neuroscience 132: 151-166.

Bird A (2007). Perceptions of epigenetics. Nature 447: 396-398.

Blundon JA, Bayazitov IT, Zakharenko SS (2011). Presynaptic gating of postsynaptically expressed plasticity at mature thalamocortical synapses. $J$ Neurosci 31: 16012-16025.

Bogdan R, Agrawal A, Gaffrey MS, Tillman R, Luby JL (2014). Serotonin transporterlinked polymorphic region (5-HTTLPR) genotype and stressful life events interact to predict preschool-onset depression: a replication and developmental extension. J Child Psychol Psychiatry 55: 448-457.

Bolten M, Nast I, Skrundz M, Stadler C, Hellhammer DH, Meinlschmidt G (2013). Prenatal programming of emotion regulation: neonatal reactivity as a differential susceptibility factor moderating the outcome of prenatal cortisol levels. J Psychosom Res 75: 351-357.

Bonin RP, De Koninck Y (2015). Reconsolidation and the regulation of plasticity: moving beyond memory. Trends Neurosci 38: 336-344.

Boyce WT (1996). Biobehavioral reactivity and injuries in children and adolescents. In: Bornstein MH, Genevro J (eds), Child Development and Behavioral Pediatrics; Toward Understanding Children and Health. Erlbaum Associates: Mahwah, NJ, pp 35-58.

Boyce WT, Alkon A, Tschann JM, Chesney MA, Alpert BS (1995a). Dimensions of psychobiologic reactivity: cardiovascular responses to laboratory stressors in preschool children. Ann Behav Med 17: 315-323.

Boyce WT, Chesney M, Alkon-Leonard A, Tschann J, Adams S, Chesterman B et al (1995b). Psychobiologic reactivity to stress and childhood respiratory illnesses: results of two prospective studies. Psychosom Med 57: 411-422.

Boyce WT, Ellis BJ (2005). Biological sensitivity to context: I. An evolutionarydevelopmental theory of the origins and functions of stress reactivity. Dev Psychopathol 17: 271-301.

Boyce WT, Essex MJ, Alkon A, Smider NA, Pickrell T, Kagan J (2002). Temperament, tympanum, and temperature: four provisional studies of the biobehavioral correlates of tympanic membrane temperature asymmetries. Child Dev 73: 718-733.

Boyce WT, Higley JD, Jemerin JJ, Champoux M, Suomi SJ (1996). Tympanic temperature asymmetry and stress behavior in rhesus macaques and children. Archiv Pediatr Adol Med 150: 518-523.

Boyce WT, Kobor MS (2015). Development and the epigenome: the 'synapse' of gene-environment interplay. Dev Sci 18: 1-23.

Boyce WT, O'Neill-Wagner P, Price CS, Haines M, Suomi SJ (1998). Crowding stress and violent injuries among behaviorally inhibited rhesus macaques. Health Psychol 17: 285-289.

Brett ZH, Sheridan MA, Jones EG, Esteves KC, Fox NA, Zeanah CH et al (2014). Association of Two ERBB3 SNP Genotypes with Sensitivity to Caregiving Context. International Society for Psychiatry Genetics: Boston, MA.

Brüne M (2012). Does the oxytocin receptor (OXTR) polymorphism (rs2254298) confer 'vulnerability' for psychopathology or 'differential susceptibility'? Insights from evolution. BMC Med 10: 38

Burns J, Svetec N, Rowe L, Mery F, Dolan M, Boyce WT et al (2012). Geneenvironment interplay in Drosophila melanogaster: chronic food deprivation in early-life affects adult exploratory and fitness traits. Proc Natl Acad Sci USA 109: 17239-17244.

Buschert J, Hohoff C, Touma C, Palme R, Rothermundt M, Arolt V et al (2013). $\mathrm{S100B}$ overexpression increases behavioral and neural plasticity in response to the social environment during adolescence. J Psychiatr Res 47: 1791-1799.

Bush N, Guendelman M, Adler N, Boyce WT (2015a, submitted to Development \& Psychopathology). BDNF allelic variants moderate social disparities in children's basal cortisol expression. 
Bush NR, Allison AL, Deardorff J, Adler NE, Boyce WT (2015b, submitted to JAMA Pediatrics). Oxytocin polymorphism and socioeconomic status interact to predict childhood obesity risk.

Byrd AL, Manuck SB (2014). MAOA, childhood maltreatment, and antisocial behavior: meta-analysis of a gene-environment interaction. Biol Psychiatry 75: 9-17.

Cacioppo JT, Uchino BN, Berntson GG (1994). Individual differences in the autonomic origins of heart rate reactivity: the psychometrics of respiratory sinus arrhythmia and preejection period. Psychophysiology 31: 412-419.

Caspi A, Hariri AR, Holmes A, Uher R, Moffitt TE (2010). Genetic sensitivity to the environment: the case of the serotonin transporter gene and its implications for studying complex diseases and traits. Am J Psychiatry 167: 509-527.

Caspi A, McClay J, Moffitt TE, Mill J, Martin J, Craig IW et al (2002). Role of genotype in the cycle of violence in maltreated children. Science 297: 851-854.

Caspi A, Sugden K, Moffitt TE, Taylor A, Craig IW, Harrington H et al (2003). Influence of life stress on depression: moderation by a polymorphism in the 5HTT gene. Science 301: 386-389.

Chang MC, Parham LD, Blanche El, Schell A, Chou C-P, Dawson M et al (2012). Autonomic and behavioral responses of children with autism to auditory stimuli. Am J Occup Ther 66: 567-576.

Chen C, Chen C, Moyzis R, Stern H, He Q, Li H et al (2011). Contributions of dopamine-related genes and environmental factors to highly sensitive personality: a multi-step neuronal system-level approach. PLoS One 6: e21636.

Cicchetti D, Toth SL, Handley ED (2015). Genetic moderation of interpersonal psychotherapy efficacy for low-income mothers with major depressive disorder: implications for differential susceptibility. Dev Psychopathol 27: 19-35.

Conradt E, Measelle J, Ablow JC (2013). Poverty, problem behavior, and promise: differential susceptibility among infants reared in poverty. Psychol Sci 24: 235-242.

Cummings EM, El-Sheikh M, Kouros CD, Keller PS (2007). Children's skin conductance reactivity as a mechanism of risk in the context of parental depressive symptoms. J Child Psychol Psychiatry 48: 436-445.

Davidson RJ (1995). Cerebral asymmetry, emotion, and affective style. In: Davidson RJ, Hugdahl K (eds), Brain Asymmetry, MIT Press: Cambridge, pp 361-387.

Davidson RJ, Hugdahl K (1995). Brain Asymmetry. The MIT Press: Cambridge, MA.

De Rubeis S, He X, Goldberg AP, Poultney CS, Samocha K, Cicek AE et al (2014). Synaptic, transcriptional and chromatin genes disrupted in autism. Nature 515: 209-215.

De Wolff MS, Van IJzendoorn MH (1997). Sensitivity and attachment: a metaanalysis on parental antecedents of infant attachment. Child Dev 68: 571-591.

Del Giudice M, Ellis BJ, Shirtcliff EA (2011). The Adaptive Calibration Model of stress responsivity. Neurosci Biobehav Rev 35: 1562-1592.

Dick DM, Agrawal A, Keller MC, Adkins A, Aliev F, Monroe S et al (2015). Candidate gene-environment interaction research: reflections and recommendations. Perspect Psychol Sci 10: 37-59.

Dissanayake DW, Mason R, Marsden CA (2013). Sensory gating, cannabinoids and schizophrenia. Neuropharmacology 67: 66-77.

Drury SS, Gleason MM, Theall KP, Smyke AT, Nelson CA, Fox NA et al (2012). Genetic sensitivity to the caregiving context: the influence of 5httlpr and BDNF val66met on indiscriminate social behavior. Physiol Behav 106: 728-735.

Duncan LE, Keller MC (2011). A critical review of the first 10 years of candidate geneby-environment interaction research in psychiatry. Am J Psychiatry 168: 1041-1049.

Duncan LE, Pollastri AR, Smoller JW (2014). Mind the gap: why many geneticists and psychological scientists have discrepant views about gene-environment interaction (GxE) research. Am Psychol 69: 249-268.

Eisenberg N, Sulik MJ, Spinrad TL, Edwards A, Eggum ND, Liew J et al (2012). Differential susceptibility and the early development of aggression: interactive effects of respiratory sinus arrhythmia and environmental quality. Dev Psychol 48: 755-768.

El-Sheikh M (2005). Stability of respiratory sinus arrhythmia in children and young adolescents: a longitudinal examination. Dev Psychobio/ 46: 66-74.

El-Sheikh M, Keller PS, Erath SA (2007). Marital conflict and risk for child maladjustment over time: skin conductance level reactivity as a vulnerability factor. J Abnorm Child Psychol 35: 715-727.

Ellis BJ, Bjorklund DF (2012). Beyond mental health: an evolutionary analysis of development under risky and supportive environmental conditions: an introduction to the special section. Dev Psychol 48: 591-597.

Ellis BJ, Boyce WT, Belsky J, Bakermans-Kranenburg MJ, Van IJzendoorn MH (2011a). Differential susceptibility to the environment: an evolutionaryneurodevelopmental theory. Dev Psychopathol 23: 7-28.

Ellis BJ, Essex MJ, Boyce WT (2005). Biological sensitivity to context: II. Empirical explorations of an evolutionary-developmental hypothesis. Dev Psychopathol 17: 303-328.
Ellis BJ, Jackson JJ, Boyce WT (2006). The stress response systems: universality and adaptive individual differences. Dev Rev 26: 175-212.

Ellis BJ, McFadyen-Ketchum S, Dodge KA, Pettit GS, Bates JE (1999). Quality of early family relationships and individual differences in the timing of pubertal maturation in girls: a longitudinal test of an evolutionary model. J Pers Soc Psychol 77: $387-401$

Ellis BJ, Shirtcliff EA, Boyce WT, Deardorff J, Essex MJ (2011b). Quality of early family relationships and the timing and tempo of puberty: effects depend on biological sensitivity to context. Dev Psychopathol 23: 85-99.

Engert V, Efanov SI, Dedovic K, Duchesne A, Dagher A, Pruessner JC (2010). Perceived early-life maternal care and the cortisol response to repeated psychosocial stress. J Psychiatry Neurosci 35: 370-377.

Essex MJ, Armstrong JM, Burk LR, Goldsmith HH, Boyce WT (2011a). Biological sensitivity to context moderates the effects of the early teacher-child relationship on the development of mental health by adolescence. Dev Psychopathol 23 $149-161$.

Essex MJ, Thomas Boyce W, Hertzman C, Lam LL, Armstrong JM, Neumann SM et al (2011b). Epigenetic vestiges of early developmental adversity: childhood stress exposure and DNA methylation in adolescence. Child Dev 84: 58-75.

Fletcher RH, Fletcher SW, Fletcher GS (2012). Clinical Epidemiology: The Essentials. Lippincott Williams \& Wilkins: Baltimore, MD.

Fortier P, Van Lieshout RJ, Waxman JA, Boyle MH, Saigal S, Schmidt LA (2014). Are orchids left and dandelions right? Frontal brain activation asymmetry and its sensitivity to developmental context. Psychol Sci 25: 1526-1533.

Fox E, Zougkou K, Ridgewell A, Garner K (2011). The serotonin transporter gene alters sensitivity to attention bias modification: evidence for a plasticity gene. Biol Psychiatry 70: 1049-1054.

Fox NA, Henderson HA, Marshall PJ, Nichols KE, Ghera MM (2005). Behavioral inhibition: linking biology and behavior within a developmental framework. Annu Rev Psychol 56: 235-262.

Fox NA, Henderson HA, Rubin KH, Calkins SD, Schmidt LA (2001). Continuity and discontinuity of behavioral inhibition and exuberance: psychophysiological and behavioral influences across the first four years of life. Child Dev 72: 1-21.

Garmezy N (1985). Stress-resistant children: the search for protective factors. In: Stevenson JE (ed), Recent Research in Developmental Psychopathology. Pergamon Press: Oxford, pp 213-233.

Gilbert SF, Epel D (2009). Ecological Developmental Biology: Integrating Epigenetics, Medicine, and Evolution. Sinauer Associates: Sunderland, MA.

Gratten J, Wray NR, Keller MC, Visscher PM (2014). Large-scale genomics unveils the genetic architecture of psychiatric disorders. Nat Neurosci 17 782-790.

Grazioplene RG, Deyoung CG, Rogosch FA, Cicchetti D (2013). A novel differential susceptibility gene: CHRNA4 and moderation of the effect of maltreatment on child personality. J Child Psychol Psychiatry 54: 872-880.

Guerra S, Martinez FD (2008). Asthma genetics: from linear to multifactorial approaches. Annu Rev Med 59: 327-341.

Gunnar MR, Frenn K, Wewerka SS, Van Ryzin MJ (2009). Moderate versus severe early life stress: associations with stress reactivity and regulation in 10-12-year-old children. Psychoneuroendocrinology 34: 62-75.

Guyer AE, Nelson EE, Perez-Edgar K, Hardin MG, Roberson-Nay R, Monk CS et al (2006). Striatal functional alteration in adolescents characterized by early childhood behavioral inhibition. J Neurosci 26: 6399-6405.

Hane AA, Fox NA (2006). Ordinary variations in maternal caregiving influence human infants' stress reactivity. Psychol Sci 17: 550-556.

Hankin BL, Nederhof E, Oppenheimer CW, Jenness J, Young JF, Abela JR et al (2011). Differential susceptibility in youth: evidence that 5-HTTLPR $\times$ positive parenting is associated with positive affect 'for better and worse'. Trans/ Psychiatry 1: e44.

Hardwick CS, Cook J (1977). Semiotics \& Significs: The Correspondence Between Charles S. Peirce \& Victoria Lady Welby. Indiana University Press: Bloomington, IN.

Herbert MR, Ziegler DA (2005). Volumetric neuroimaging and low-dose early-life exposures: loose coupling of pathogenesis-brain-behavior links. Neurotoxicology 26: $565-572$.

Herculano-Houzel S (2009). The human brain in numbers: a linearly scaled-up primate brain. Front Hum Neurosci 3: 31.

Holstein DH, Vollenweider FX, Geyer MA, Csomor PA, Belser N, Eich D (2013). Sensory and sensorimotor gating in adult attention-deficit/hyperactivity disorder (ADHD). Psychiatry Res 205: 117-126.

Hosang GM, Shiles C, Tansey KE, McGuffin P, Uher R (2014). Interaction between stress and the BDNF Val66Met polymorphism in depression: a systematic review and meta-analysis. BMC Med 12: 7 
Jagiellowicz J, Xu X, Aron A, Aron E, Cao G, Feng T et al (2011). The trait of sensory processing sensitivity and neural responses to changes in visual scenes. Soc Cogn Affect Neurosci 6: 38-47.

Johnson MR, Adler LE (1993). Transient impairment in P50 auditory sensory gating induced by a cold-pressor test. Biol Psychiatry 33: 380-387.

Kagan J (1989). Temperamental contributions to social behavior. Am Psychol 44: 668-674.

Kagan J (1994). Galen's Prophecy. Basic Books: New York.

Kagan J, Reznick JS, Snidman N (1988). Biological bases of childhood shyness. Science 240: 167-171.

Kant I (1800). Anthropology from a Pragmatic Point of View. Berlin Academy. Berlin, Germany.

Katsanis J, lacono WG, McGue MK, Carlson SR (1997). P300 event-related potential heritability in monozygotic and dizygotic twins. Psychophysiology 34: 47-58.

Kim-Cohen J, Caspi A, Taylor A, Williams B, Newcombe R, Craig IW et al (2006). MAOA, maltreatment, and gene-environment interaction predicting children's mental health: new evidence and a meta-analysis. Mol Psychiatry 11: 903-913.

Klengel T, Mehta D, Anacker C, Rex-Haffner M, Pruessner JC, Pariante CM et al (2013). Allele-specific FKBP5 DNA demethylation mediates gene-childhood trauma interactions. Nat Neurosci 16: 33-41.

Knafo A, Israel S, Ebstein RP (2011). Heritability of children's prosocial behavior and differential susceptibility to parenting by variation in the dopamine receptor D4 gene. Dev Psychopathol 23: 53-67.

Kohl S, Heekeren K, Klosterkotter J, Kuhn J (2013). Prepulse inhibition in psychiatric disorders-apart from schizophrenia. J Psychiatr Res 47: 445-452.

Koolhaas J, Korte S, De Boer S, Van Der Vegt B, Van Reenen C, Hopster H et al (1999). Coping styles in animals: current status in behavior and stress-physiology. Neurosci Biobehav Rev 23: 925-935.

Kouros CD, Cummings EM, Davies PT (2010). Early trajectories of interparental conflict and externalizing problems as predictors of social competence in preadolescence. Dev Psychopathol 22: 527-537.

Kraemer HC (2012). Determining gene moderation of environmental risk factors for a mental disorder: a 'perfect storm' of methodological problems. Int J Methods Psychiatr Res 21: 185-194.

Kraemer HC, Stice E, Kazdin A, Offord D, Kupfer D (2001). How do risk factors work together? Mediators, moderators, independent, overlapping and proxy-risk factors. Am J Psychiatry 158: 848-856.

Larrimore MJ (2001). Substitutes for wisdom: Kant's practical thought and the tradition of the temperaments. J Hist Philos 39: 259-288.

Laucht M, Blomeyer D, Buchmann AF, Treutlein J, Schmidt MH, Esser G et al (2012). Catechol-O-methyltransferase Val158 Met genotype, parenting practices and adolescent alcohol use: testing the differential susceptibility hypothesis. $J$ Child Psychol Psychiatry 53: 351-359.

Leppanen JM, Nelson CA (2009). Tuning the developing brain to social signals of emotions. Nat Rev Neurosci 10: 37-47.

Lorber MF, Erlanger AC, Slep AM (2013). Biological sensitivity to context in couples: why partner aggression hurts some more than others. J Consult Clin Psychol 81: 166-176.

Maes M, Ringel K, Kubera M, Berk M, Rybakowski J (2012). Increased autoimmune activity against 5-HT: a key component of depression that is associated with inflammation and activation of cell-mediated immunity, and with severity and staging of depression. J Affect Disord 136: 386-392.

Manuck SB, Craig AE, Flory JD, Halder I, Ferrell RE (2011). Reported early family environment covaries with menarcheal age as a function of polymorphic variation in estrogen receptor-alpha. Dev Psychopathol 23: 69-83.

Manuck SB, McCaffery JM (2014). Gene-environment interaction. Annu Rev Psychol 65: 41-70.

Marigorta UM, Gibson G (2014). A simulation study of gene-by-environment interactions in GWAS implies ample hidden effects. Front Genet 5: 225.

Matthews KA, Woodall KL, Stoney CM (1990). Changes in and stability of cardiovascular responses to behavioral stress: results from a four-year longitudinal study of children. Child Dev 61: 1134-1144.

McGilchrist I (2009). The Master and His Emissary: The Divided Brain and the Making of the Western World. Yale University Press: New Haven.

Meaney MJ (2001). Maternal care, gene expression, and the transmission of individual differences in stress reactivity across generations. Annu Rev Neurosci 24: 1161-1192.

Meaney MJ (2010). Epigenetics and the biological definition of gene $x$ environment interactions. Child Dev 81: 41-79.

Mehta D, Klengel T, Conneely KN, Smith AK, Altmann A, Pace TW et al (2013). Childhood maltreatment is associated with distinct genomic and epigenetic profiles in posttraumatic stress disorder. Proc Natl Acad Sci USA 110: 8302-8307.
Merton RK (1973). The Sociology of Science: Theoretical and Empirical Investigations. University of Chicago Press: Chicago.

Miller L (2000). Neurosensitization: a model for persistent disability in chronic pain, depression, and posttraumatic stress disorder following injury. NeuroRehabilitation 14: 25-32.

Missana M, Atkinson AP, Grossmann T (2014). Tuning the developing brain to emotional body expressions. Dev Sci 18: 243-253.

Missana M, Grossmann T (2015). Infants' emerging sensitivity to emotional body expressions: insights from asymmetrical frontal brain activity. Dev Psychol 51: $151-160$

Mitchell C, Hobcraft J, McLanahan SS, Siegel SR, Berg A, Brooks-Gunn J et al (2014). Social disadvantage, genetic sensitivity, and children's telomere length. Proc Natl Acad Sci USA 111: 5944-5949.

Monroe SM, Harkness KL (2005). Life stress, the 'kindling' hypothesis, and the recurrence of depression: considerations from a life stress perspective. Psychol Rev 112: 417-445.

Montirosso R, Provenzi L, Tavian D, Morandi F, Bonanomi A, Missaglia S et al (2015). Social stress regulation in 4-month-old infants: contribution of maternal social engagement and infants' 5-HTTLPR genotype. Early Hum Dev 91: 173-179.

Myles-Worsley M, Coon H, Byerley W, Waldo M, Young D, Freedman R (1996). Developmental and genetic influences on the P50 sensory gating phenotype. Biol Psychiatry 39: 289-295.

Nederhof E, Schmidt MV (2012). Mismatch or cumulative stress: toward an integrated hypothesis of programming effects. Physiol Behav 106: 691-700.

Neylan TC, Fletcher DJ, Lenoci M, McCallin K, Weiss DS, Schoenfeld FB et al (1999). Sensory gating in chronic posttraumatic stress disorder: reduced auditory P50 suppression in combat veterans. Biol Psychiatry 46: 1656-1664.

Nieuwenhuis S, Aston-Jones G, Cohen JD (2005). Decision making, the P3, and the locus coeruleus-norepinephrine system. Psychol Bull 131: 510-532.

Obradovic J, Bush NR, Boyce WT (2011). The interactive effect of marital conflict and stress reactivity on externalizing and internalizing symptoms: the role of laboratory stressors. Dev Psychopathol 23: 101-114.

Obradovic J, Bush NR, Stamperdahl J, Adler NE, Boyce WT (2010). Biological sensitivity to context: the interactive effects of stress reactivity and family adversity on socio-emotional behavior and school readiness. Child Dev 81: 270-289.

Olden K, Lin YS, Gruber D, Sonawane B (2014). Epigenome: biosensor of cumulative exposure to chemical and nonchemical stressors related to environmental justice. Am J Public Health 104: 1816-1821.

Patterson JV, Hetrick WP, Boutros NN, Jin Y, Sandman C, Stern H et al (2008). P50 sensory gating ratios in schizophrenics and controls: a review and data analysis. Psychiatry Res 158: 226-247.

Percy W (1991). Signposts in a Strange Land. Farrar, Straus \& Giroux: New York.

Pluess M, Belsky J (2011). Prenatal programming of postnatal plasticity? Dev Psychopathol 23: 29-38.

Pluess M, Belsky J (2012). Vantage sensitivity: individual differences in response to positive experiences. Psychol Bull 139: 901-916.

Poehlmann J, Schwichtenberg AJ, Shlafer RJ, Hahn E, Bianchi JP, Warner R (2011). Emerging self-regulation in toddlers born preterm or low birth weight: differential susceptibility to parenting? Dev Psychopathol 23: 177-193.

Powell SB, Weber M, Geyer MA (2012). Genetic models of sensorimotor gating: relevance to neuropsychiatric disorders. Curr Top Behav Neurosci 12: 251-318.

Qiu A, Tuan TA, Ong ML, Li Y, Chen H, Rifkin-Graboi A et al (2015). COMT haplotypes modulate associations of antenatal maternal anxiety and neonatal cortical morphology. Am J Psychiatry 172: 163-172.

Quas JA, Bauer A, Boyce WT (2004). Physiological reactivity, social support, and memory in early childhood. Child Dev 75: 797-814.

Quas JA, Yim IS, Oberlander TF, Nordstokke D, Essex MJ, Armstrong JM et al (2014). The symphonic structure of childhood stress reactivity: patterns of sympathetic, parasympathetic, and adrenocortical responses to psychological challenge. Dev Psychopathol 26: 963-982.

Reiss D, Leve LD, Neiderhiser JM (2013). How genes and the social environment moderate each other. Am J Public Health 103: S111-S121.

Rietveld CA, Medland SE, Derringer J, Yang J, Esko T, Martin NW et al (2013). GWAS of 126,559 individuals identifies genetic variants associated with educational attainment. Science 340: 1467-1471.

Risch N, Herrell R, Lehner T, Liang KY, Eaves L, Hoh J et al (2009). Interaction between the serotonin transporter gene (5-HTTLPR), stressful life events, and risk of depression: a meta-analysis. Jama 301: 2462-2471.

Rose G (1985). Sick individuals and sick populations. Int J Epidemiol 14: 32-38.

Rothbart MK, Bates JE (1998). Temperament. In: Damon W, Eisenberg N (eds), Handbook of Child Psychology: Volume 3. Social, Emotional, and Personality Development, 5th edn, Vol 3. Wiley: New York, pp 105-178. 
Rothman KJ, Greenland S (2005). Causation and causal inference in epidemiology. Am J Public Health 95: S144-S150.

Rudolph KD, Troop-Gordon W, Granger DA (2010). Peer victimization and aggression: moderation by individual differences in salivary cortisol and alphaamylase. J Abnorm Child Psychol 38: 843-856.

Rule RR, Shimamura AP, Knight RT (2002). Orbitofrontal cortex and dynamic filtering of emotional stimuli. Cogn Affect Behav Neurosci 2: 264-270.

Rutter M (2006). Genes and Behaviour: Nature/Nurture Interplay Explained. Blackwell Publishing: Oxford, UK.

Rutter M, Thapar A, Pickles A (2009). Gene-environment interactions: biologically valid pathway or artifact? Arch Gen Psychiatry 66: 1287-1289.

Santra T (2014). A bayesian framework that integrates heterogeneous data for inferring gene regulatory networks. Front Bioeng Biotechnol 2: 13.

Scott S, O'Connor TG (2012). An experimental test of differential susceptibility to parenting among emotionally-dysregulated children in a randomized controlled trial for oppositional behavior. J Child Psychol Psychiatry 53: 1184-1193.

Seery MD, Holman EA, Silver RC (2010). Whatever does not kill us: cumulative lifetime adversity, vulnerability, and resilience. J Personality Soc Psychol 99: 1025-1041.

Shannon KE, Beauchaine TP, Brenner SL, Neuhaus E, Gatzke-Kopp L (2007). Familial and temperamental predictors of resilience in children at risk for conduct disorder and depression. Dev Psychopathol 19: 701-727.

Simons RL, Lei MK, Beach SR, Brody GH, Philibert RA, Gibbons FX (2011). Social environmental variation, plasticity genes, and aggression: evidence for the differential susceptibility hypothesis. Am Soc Rev 76: 833-912.

Sipahi L, Uddin M, Hou ZC, Aiello AE, Koenen KC, Galea S et al (2014a). Ancient evolutionary origins of epigenetic regulation associated with posttraumatic stress disorder. Front Hum Neurosci 8: 284.

Sipahi L, Wildman DE, Aiello AE, Koenen KC, Galea S, Abbas A et al (2014b). Longitudinal epigenetic variation of DNA methyltransferase genes is associated with vulnerability to post-traumatic stress disorder. Psychol Med 44: 3165-3179.

Sokolowski MB (2010). Social interactions in 'simple' model systems. Neuron 65: 780-794.

Stevens KE, Bullock AE, Collins AC (2001). Chronic corticosterone treatment alters sensory gating in C3H mice. Pharmacol Biochem Behav 69: 359-366.

Strunk T, Jamieson SE, Burgner D (2013). Genetic and epigenetic susceptibility to early life infection. Curr Opin Infect Dis 26: 241-247.

Sturge-Apple ML, Cicchetti D, Davies PT, Suor JH (2012). Differential susceptibility in spillover between interparental conflict and maternal parenting practices: evidence for OXTR and 5-HTT genes. J Fam Psychol 26: 431-442.

Suderman M, McGowan PO, Sasaki A, Huang TC, Hallett MT, Meaney MJ et al (2012). Conserved epigenetic sensitivity to early life experience in the rat and human hippocampus. Proc Natl Acad Sci USA 109: 17266-17272.

Suomi SJ (1987). Genetic and maternal contributions to individual differences in Rhesus monkey biobehavioral development. In: Krasnagor N (ed), Psychobiological Aspects of Behavioral Development. Academic Press: New York, pp 397-419.

Sweitzer MM, Halder I, Flory JD, Craig AE, Gianaros PJ, Ferrell RE et al (2013). Polymorphic variation in the dopamine D4 receptor predicts delay discounting as a function of childhood socioeconomic status: evidence for differential susceptibility. Soc Cogn Affect Neurosci 8: 499-508.

Szczepanski SM, Knight RT (2014). Insights into human behavior from lesions to the prefrontal cortex. Neuron 83: 1002-1018.

Szyf M (2013). How do environments talk to genes? Nat Neurosci 16: 2-4.

Talge NM, Donzella B, Gunnar MR (2008). Fearful temperament and stress reactivity among preschool-aged children. Infant Child Dev 17: 427-445

Taylor A, Kim-Cohen J (2007). Meta-analysis of gene-environment interactions in developmental psychopathology. Dev Psychopathol 19: 1029-1037.

Taylor SE, Way BM, Welch WT, Hilmert CJ, Lehman BJ, Eisenberger NI (2006). Early family environment, current adversity, the serotonin transporter polymorphism, and depressive symptomatology. Biological Psychiatry 60: 671-676.
Teh AL, Pan H, Chen L, Ong ML, Dogra S, Wong J et al (2014). The effect of genotype and in utero environment on inter-individual variation in neonate DNA methylomes. Genome Res 24: 1064-1074.

Thomas A, Chess S (1984). Genesis and evolution of behavioral disorders: from infancy to early adult life. Am J Psychiatry 141: 1-9.

Thomas MR, Wara D, Saxton K, Truskier M, Chesney MA, Boyce WT (2013). Family adversity and autonomic reactivity association with immune changes in HIVaffected school children. Psychosom Med 75: 557-565.

Turkheimer E (1998). Heritability and biological explanation. Psychol Rev 105: 782-791

Uddin M, Aiello AE, Wildman DE, Koenen KC, Pawelec G, de Los Santos R et al (2010). Epigenetic and immune function profiles associated with posttraumatic stress disorder. Proc Natl Acad Sci USA 107: 9470-9475.

Van Bockstaele EJ, Reyes BA, Valentino RJ (2010). The locus coeruleus: a key nucleus where stress and opioids intersect to mediate vulnerability to opiate abuse. Brain Res 1314: 162-174.

Van IJzendoorn MH, Bakermans-Kranenburg MJ (2012a). Differential susceptibility experiments: going beyond correlational evidence: comment on beyond mental health, differential susceptibility articles. Dev Psychol 48: 769-774.

Van IJzendoorn MH, Belsky J, Bakermans-Kranenburg MJ (2012b). Serotonin transporter genotype 5HTTLPR as a marker of differential susceptibility? A metaanalysis of child and adolescent gene-by-environment studies. Transl Psychiatry 2: e147.

van Winkel M, Peeters F, van Winkel R, Kenis G, Collip D, Geschwind N et al (2014). Impact of variation in the BDNF gene on social stress sensitivity and the buffering impact of positive emotions: replication and extension of a gene-environment interaction. Eur Neuropsychopharmacol 24: 930-938.

VanZomeren-Dohm AA, Pitula CE, Koss KJ, Thomas K, Gunnar MR (2015). FKBP5 moderation of depressive symptoms in peer victimized, post-institutionalized children. Psychoneuroendocrinology 51: 426-430.

Vlcek P, Bob P, Raboch J (2014). Sensory disturbances, inhibitory deficits, and the P50 wave in schizophrenia. Neuropsychiatr Dis Treat 10: 1309-1315.

Wachs TD (1983). The use and abuse of environment in behavior-genetic research. Child Dev 54: 396-407.

Wetmur JG, Lehnert G, Desnick RJ (1991). The delta-aminolevulinate dehydratase polymorphism: higher blood lead levels in lead workers and environmentally exposed children with the 1-2 and 2-2 isozymes. Environ Res 56: 109-119.

Whittle S, Yap MB, Sheeber L, Dudgeon P, Yucel M, Pantelis C et al (2010). Hippocampal volume and sensitivity to maternal aggressive behavior: a prospective study of adolescent depressive symptoms. Dev Psychopathol 23: $115-129$

Willms JD (2002). Vulnerable Children: Findings from the National Longitudinal Study of Children and Youth. University of Alberta Press: Edmonton, Alberta, Canada.

Willner P, Scheel-Krüger J, Belzung C (2013). The neurobiology of depression and antidepressant action. Neurosci Biobehav Rev 37: 2331-2371.

Windhorst DA, Mileva-Seitz VR, Linting M, Hofman A, Jaddoe WW, Verhulst FC et al (2015). Differential susceptibility in a developmental perspective: DRD4 and maternal sensitivity predicting externalizing behavior. Dev Psychobiol 57: 35-49.

Witt SH, Buchmann AF, Blomeyer D, Nieratschker V, Treutlein J, Esser G et al (2011). An interaction between a neuropeptide $Y$ gene polymorphism and early adversity modulates endocrine stress responses. Psychoneuroendocrinology 36: 1010-1020.

Xiong H, Krugers HJ (2015). Tuning hippocampal synapses by stress-hormones: relevance for emotional memory formation. Brain Res 1621: 114-120.

Yap MB, Whittle S, Yucel M, Sheeber L, Pantelis C, Simmons JG et al (2008). Interaction of parenting experiences and brain structure in the prediction of depressive symptoms in adolescents. Arch Gen Psychiatry 65: 1377-1385.

Zelazo PD, Carlson SM (2012). Hot and cool executive function in childhood and adolescence: Development and plasticity. Child Dev Perspect 6: 354-360.

Zohsel K, Buchmann AF, Blomeyer D, Hohm E, Schmidt MH, Esser G et al (2014). Mothers' prenatal stress and their children's antisocial outcomes-a moderating role for the dopamine D4 receptor (DRD4) gene. J Child Psychol Psychiatry 55: 69-76. 